\title{
Worker well-being before and during the COVID-19 restrictions: A longitudinal study in the UK
}

\author{
Diane Pelly ${ }^{1}$ \\ Michael Daly ${ }^{2}$ \\ Liam Delaney $^{3}$ \\ Orla Doyle
}

\begin{abstract}
The potential impact of COVID-19 restrictions on worker well-being is currently unknown. In this study we examine 15 well-being outcomes collected from 621 full-time workers assessed before (November, 2019 - February, 2020) and during (May-June, 2020) the COVID-19 pandemic. Fixed effects analyses are used to investigate how the COVID-19 restrictions and involuntary homeworking affect well-being and job performance. The majority of worker wellbeing measures are not adversely affected. Homeworkers feel more engaged and autonomous, experience fewer negative emotions and feel more connected to their organisations. However, these improvements come at the expense of reduced homelife satisfaction and job performance.
\end{abstract}

JEL codes: J08; J24; I31

Keywords: COVID-19 restrictions; workers; homeworking; subjective well-being; productivity; mental health; job satisfaction; engagement

\footnotetext{
${ }^{1}$ Corresponding Author; School of Economics, University College Dublin. Email: diane.pelly@ucdconnect.ie;:

${ }^{2}$ Department of Psychology, Maynooth University.Email: Michael.A.Daly@mu.ie

${ }^{3}$ Behavioural Science Unit, London School of Economics. Email: L.D.Delaney@lse.ac.uk

${ }^{4}$ School of Economics, University College Dublin. Emails: orla.doyle@ucd.ie

This study was approved by the University College Dublin (UCD) Human Research Ethics Committee. Funding from the Irish Research Council (Diane Pelly, Grant number: GOIPG/2020/59) and the UCD Behavioural Science Group is gratefully acknowledged.
} 


\section{Introduction}

A burgeoning interdisciplinary literature has examined the impact of COVID-19 on well-being. However, current understanding of this topic is limited as most existing studies rely almost exclusively on data collected after the onset of the pandemic and utilise a narrow set of wellbeing measures. The current study contributes to this literature by producing a rich account of the well-being experiences of UK employees, surveyed before and during the imposition of COVID-19 restrictions. The pre-post pandemic design allows us to estimate the effects of 'lockdown' and in particular, the dramatic shift to homeworking, across a wide range of worker well-being measures.

On the $16^{\text {th }}$ of March 2020, against a backdrop of rising deaths and hospital admissions, the UK Prime Minister advised people to refrain from non-essential travel and physical contact with others and to work from home where possible. ${ }^{5}$ One week later, this advice was upgraded to a statutory ban on leaving the home, including commuting to work, unless workers were unable to work from home and commuting was "absolutely necessary". The UK remained in lockdown for eleven weeks, with a phased re-opening of the economy in June and July. Figure 1 depicts the timeline. The aim of this study is to assess the emotional and psychological reactions of full-time workers to this exogenous shock.

The impact of exogenous shocks (e.g. Berlemann, 2016) and pandemics in particular (e.g. Lau et al., 2008) on well-being is well documented. Many of these studies, as well as more recent COVID-19 works, are however limited by cross-sectional designs, an absence of prepandemic baseline data, or by a reliance on narrow, single-item measures of subjective wellbeing. To date, COVID-19 well-being studies have largely focused on the general population (e.g. Pierce et al, 2020) or on specific groups of interest such as frontline healthcare workers or those with pre-existing health conditions (e.g. Cabarkapa et al., 2020). Of the studies

\footnotetext{
${ }^{5}$ By that stage a large shift towards homeworking had already occurred e.g. Hearn (2020).
} 
examining workers, most focus on the distributional effects of COVID-19-related unemployment and changes in income (e.g. Bell and Blanchflower, 2020). Few studies have focused on the impact of COVID-19 on the subjective well-being of full-time workers who remain in employment. This group is of crucial interest in the context of COVID-19 given the dramatic shift to homeworking. Full-time workers form the majority of the labour force and they have been subjected to a dual shock - the impact of the pandemic itself and, for many, a radical change in where and how they work. ${ }^{6}$

Similarly, few studies specifically examine the well-being effects of homeworking due to COVID-19 restrictions, with the majority of studies identifying who can work from home (e.g. Dingel and Neiman, 2020), rather than examining the lived experience of workers who are working from home due to COVID-19. With some exceptions ${ }^{7}$, the small set of studies that specifically examine the well-being of homeworkers during the pandemic rely largely on measures of psychological distress and many lack pre-pandemic data. In contrast, in this study we use longitudinal data and adopt a broad view of subjective worker well-being. We identify three aspects that may be impacted by COVID-19 restrictions and homeworking: how people evaluate their lives (e.g. life satisfaction), how people feel from moment-to-moment (e.g. happiness), and their eudaimonic well-being (e.g. sense of meaning and purpose). We examine changes in each of these aspects both before (November - February, 2020) and during (May June, 2020) the COVID-19 restrictions in the UK. Furthermore, we isolate the moderating effect of homeworking by comparing the changes in well-being among workers who worked from home during lockdown to the changes experienced by those who continued to work from their pre-COVID-19 location. We demonstrate that work-related well-being significantly improves during the period of restrictions. However, there is considerable heterogeneity, with

\footnotetext{
${ }^{6}$ Worker well-being is associated with labour market behaviour such as voluntary turnover e.g. Caesens, Stinglhamber and Marmier (2016). ${ }^{7}$ E.g. Zacher and Rudolph (2020); Recchi et al (2020); Moehring et al (2020); Felstead and Reuschke (2020).
} 
homeworkers benefitting more in terms of enhanced psychological and emotional well-being, albeit at the cost of lower home-life satisfaction and job performance.

This paper contributes to multiple research strands. Firstly, we make a unique contribution to the COVID-19 literature by using a fixed effects model to examine the impact of an exogenous shock on workers' cognitive (evaluative), emotional and psychological (eudaimonic) work-related well-being. Secondly, we contribute to the homeworking literature by comparing changes in well-being experienced by non-homeworkers and homeworkers during the pandemic, with the caveat that many homeworkers may not have self-selected into homeworking. In addition, for the first time, we capture the lived reality of day-to-day homeworking before and during the COVID-19 restrictions using the Day Reconstruction Method ("DRM”) (Kahneman et al., 2004). In doing so we acknowledge that being compelled to work from home, while perhaps simultaneously caring for children / home-schooling, may constitute a very different experience to actively choosing to work from home under 'normal' circumstances.

We identify significant changes in 8 of the 15 baseline well-being measures administered over a reasonably short window (3-6 months) for the overall sample. ${ }^{8}$ The results demonstrate that worker well-being appears to be influenced by contextual forces, even after stable, individual differences are accounted for. We report larger effects for homeworkers (significant changes in 8 measures) than non-homeworkers (significant change in just 1 measure). We also identify a significant change in self-rated job performance for homeworkers.

The remainder of the paper is organised as follows: Section 2 summarises the relevant literature and our contribution. Section 3 describes the data and outlines the empirical strategy.

\footnotetext{
${ }^{8}$ Adjusted Benjamimi-Hockberg p-values are used throughout
} 
Section 4 depicts the main results and robustness tests. Section 5 discusses our results and concludes.

\section{Background}

This paper examines how an exogenous shock (COVID-19 restrictions) affects the well-being of full-time workers. COVID-19 studies to date generally measure psychological distress and mental health symptoms in the general population and do not focus specifically on workers. Depression, anxiety and stress are found to be common global reactions to the early stages of the pandemic (Rajkumar, 2020; Wang et al, 2020), with women and young adults particularly affected (Daly and Robinson, 2020; Pierce et al, 2020). There is however emerging evidence of psychological adaptation. For example, Daly, Sutin, \& Robinson (2020) use the Understanding Society data to show that mental health partly recovered in May and June in the UK. Similarly, Fancourt, Steptoe and Bu (2020) report that, while 49\% of respondents in the UK report high anxiety at the start of lockdown, compared to $21 \%$ at the end of 2019 , this falls to $30 \%$ by September. Depression rates also fall steadily. However, young adults and ethnic minorities continue to be disproportionately affected. Similarly, in the US, Daly and Robinson (2020) find that an initial sharp rise in psychological distress in early-April is followed by a return to baseline levels by June, while Globig, Blain and Sharot (2020) find positive affect of US respondents returns to baseline within one month.

A limited number of pre-post outbreak studies examine the trajectory of other wellbeing outcomes during the COVID-19 restrictions. Lockdown is associated with reduced life satisfaction in Italy (e.g. Ruggieri et al, 2020) and increased stress at home in Canada (Beland et al., 2020). In the UK, Fancourt et al. (2020) show that, while average life satisfaction is significantly lower than usual prior to lockdown, it increases after lockdown is announced and stabilises by the end of May, albeit at a lower level. This also lends support to an adaptation theory. Their findings also suggest that lockdown is not necessarily a negative experience for 
everyone, with one third of respondents (mainly those with higher incomes and who live with others) 'enjoying lockdown'. Similarly, Recchi et al., (2020) report higher levels of self-rated health and well-being amongst French respondents from higher socio-economic backgrounds, a finding they attribute to unaffected individuals rating their life situations more favourably. For other groups however, lockdown is associated with increased domestic discord (e.g. Luetke et al., 2020; Heubener et al., 2020).

Very few studies focus exclusively on the impact of lockdown on worker well-being. One notable exception is Zacher and Rudolph's (2020) study which finds a significant decrease in life satisfaction and positive affect amongst German workers during the early stages of the pandemic. Against expectations, they also find a reduction in negative affect. They attribute this to coping strategies and positive reframing, as well as to a potential increase in lowactivation negative emotions. Our study advances this work by analysing a wider range of emotions, allowing us to provide a more nuanced insight into the affective mechanisms at work.

For a large portion of UK workers, lockdown triggered a sudden switch to homeworking. Prior to COVID-19, just $2 \%$ of our sample worked from home full-time. This figure increased to $74 \%$ during lockdown. Preferences for homeworking are well documented (Author Reference, 2020; Wheatley, 2020). ${ }^{9}$ However, the extent to which prior attitudes towards homeworking translate into lived experience, particularly when homeworking is imposed rather than actively chosen, is largely unknown. While homeworking is usually positively associated with job satisfaction, and organisational commitment, the relationship between homeworking, stress and emotional well-being is largely unknown (Charalompous et al, 2017; Oakman et al, 2020). The relationship between homeworking and burnout is also unclear. While Anderson and Kelliher (2009) find higher levels of engagement amongst

\footnotetext{
${ }^{9}$ Reasons why workers might prefer homeworking include no commute; more flexibility etc. Reasons why workers might prefer not to work from home include feeling isolated etc.
} 
homeworkers, homeworkers may also be more susceptible to exhaustion due to reciprocityinduced increased work-effort (Canonico, 2016).

The homeworking literature discussed thus far relates to self-selected homeworking under 'normal' circumstances. COVID-19 studies show that workers' lived experiences of homeworking are characterised by heterogeneity. Lyttleton, Zang and Musick (2020) find that homeworking mothers feel anxious, lonely and depressed more often than homeworking fathers. On the other hand, Moehring et al. (2020) find no association between switching to homeworking and changes in homelife or job satisfaction amongst German workers.

In relation to homeworking and performance, while Bloom et al's (2015) wellpublicised randomised controlled trial finds a positive association between homeworking and productivity pre-COVID-19, the results from COVID-19 studies are more equivocal. Baudot and Kelly (2020) report an increase in US workers' rating of their own and subordinates' performance and Baert et al. (2020) find that just under half of Flemish homeworkers report lower stress, higher concentration and believe they are less likely to suffer from future burnout. The authors speculate that this may be due to the perceived support that workers received from their organisations during lockdown, a factor which is linked to successful flexible working (Allen, 2001; Oakman et al. 2020). In the UK, Felstead and Reuschke (2020) find that 30\% of Understanding Society workers report reduced productivity compared to pre-COVID levels, whereas $29 \%$ report getting more work done.

While most COVID-19 well-being studies rely on psychological distress or life satisfaction measures, our study reflects the New Economics Foundation definition of worker wellbeing, namely "feeling good and functioning well" (White, 2000). In line with a vast literature (summarised in DeSimone, 2014), we view subjective worker well-being as a multidimensional construct which includes two separable and independent constructs - a relatively stable cognitive (evaluative) component and a transient emotional component. In 
addition, we acknowledge a growing body of evidence from positive psychology (e.g. Diener et al., 2018; Ryan and Deci, 2001) which suggests that subjective well-being should be expanded to include psychological well-being. ${ }^{10}$ In the context of workers, this captures the "affective and purposive psychological state that people experience while they are at work" (Robertson and Cooper, 2011 p.54).

The measures we employ reflect a growing consensus that workers need to feel emotionally connected to their colleagues (relatedness) and to achieve 'mastery' over their working environment through goals which are consistent with their sense of self (autonomy) and ability (competence) (Ryff, 1989; Reis et al., 2000). To perform optimally, workers also need to feel engaged, a state which arises when they experience high-activation positive emotions and find their work absorbing (Csikszentmihalyi, 1990), worthwhile (Seligman, 2018) and positively challenging (Bakker and Demerouti, 2008). Workers who experience low levels of pleasure and activation may feel 'burnt out', a state characterised by emotional exhaustion, chronic fatigue and a cynical attitude (Bakker and Oerlemans, 2011). Workers in our sample may thus report high well-being if they experience positive emotions frequently and unhappy emotions infrequently; if they are satisfied with her work-life relative to that of their peers, past experiences and future expectations (Bakker and Oerlemans, 2011); if they feel engaged; if they feel emotionally connected to her colleagues and if they can function well in the workplace and realise their potential.

Whereas well-being surveys predominantly employ single-item job satisfaction scales, affective measures vary widely. Global (evaluative) measures capture workers' beliefs about the typical, overall patterns of emotions experienced at work, on a remembered basis (Bakker and Oerlemans, 2011). Experiential measures capture momentary affective states triggered by external circumstances, as they occur. Despite evidence that these measures are differentially

${ }^{10}$ Factor analyses (e.g. Linley et al, 2009) show that subjective well-being and psychological well-being load separately onto two independent but related factors 
determined (Hudson, Lucas and Donnellan, 2016) and that experiential measures are associated with economically relevant behaviour (e.g. Binnewies, Sonnentag and Mojza, 2009), global measures continue to dominate the literature. This paper addresses this discrepancy by using both global and experiential measures to investigate the extent to which different aspects of well-being are determined by "transitory versus enduring factors" (Hudson, Lucas and Donnellan, 2017 p.45).

This paper uses cognitive, emotional and psychological measures to explore the trajectory of worker well-being and performance pre- and during the imposition of COVID-19 restrictions and enforced homeworking in the UK. Given the well-documented links between global measures and enduring life circumstances, we do not expect to observe meaningful changes in global within-person satisfaction or affect given our sample, who are on average highly educated, full-time workers, on permanent contracts. In contrast, we expect experiential measures to be more sensitive to the contextual change in working-life circumstances induced by the COVID-19 restrictions.

\section{METHOD}

\subsection{Data and Sample}

We use balanced, longitudinal panel data for 621 full-time workers based on two in-depth, surveys specifically designed to measure worker well-being. Participants were sourced through Prolific Academic, a specialist academic research survey-panel provider. The baseline survey was completed online by 994 workers in the UK between $25^{\text {th }}$ of November,2019 and the $19^{\text {th }}$ of February,2020. ${ }^{11}$

The second, follow-up survey, was restricted to workers who participated in the first survey. Matched data was collected from 741 respondents between the $7^{\text {th }}$ of May and the $3^{\text {rd }}$

\footnotetext{
${ }^{11}$ During Wave 2 three workers are based in Northern Ireland and three workers in the Republic of Ireland. Excluding these workers from
} the analysis does not affect the results materially. 
of July, 2020. The distribution of responses by month is graphed in $\underline{\mathrm{S} 1}$ of the Online Supplementary Materials. 94\% of Wave 2 responses were obtained in May, 5\% in June and just 1 response in July. The majority were collected during full lockdown, on the $7^{\text {th }}$ and $8^{\text {th }}$ of May, immediately prior to the publishing of the Conditional Plan to re-open schools and society. 25 responses were obtained between the $1^{\text {st }}$ and $19^{\text {th }}$ of June, a period which coincides with lockdown easing, including phased school re-openings. Just 8 responses were obtained after the risk level was lowered to 'general risk' on the $19^{\text {th }}$ of June.

The sample was designed to target full-time workers. Pre-screening criteria were used to recruit workers who were between 18 and 65 years old and who were engaged in full-time paid employment for more than 2 months, in organisations with 5 or more workers, for at least 21 hours per week. Shift-/ part-time workers and the self-employed were excluded due to evidence that they experience different health (Reutrakul and Knutson, 2015), productivity (Folkard and Tucker, 2003) and lower job quality (Wheatley, 2020) patterns. 120 workers were excluded as they were no longer engaged in paid work at the time of the follow-up survey ${ }^{12}$. The final sample comprises 621 full-time workers.

While our sample is not nationally representative, Wheatley's (2020) study using the Understanding Society data suggests that our sample reflects the UK homeworking population which are more likely to be middle-aged, highly qualified, living with children and on a permanent contract. $\underline{\mathrm{S} 2}$ in the Online Supplementary Materials compares the key demographic variables of the full-time workers in our sample to those used by Wheatley (2020).

The descriptive characteristics are set out in Table 1 and Table 2. Prior to COVID-19, only $2 \%$ of the sample were fully homeworking, which is in line with Wheatley (2020). At this time, $17 \%$ of our sample worked from home frequently (at least 4 days per month), $13 \%$ worked

\footnotetext{
${ }^{12} 6$ workers were on maternity or sick leave during wave 2. The remaining 114 workers were on temporary leave or had lost their jobs. Unemployed workers are excluded due to an extensive literature which links unemployment with systematically lower well-being e.g. Lucas et al (2004); Winkelman and Winkelman (1998).
} 
from home sometimes (less than 1 day per month but more than 4 days per year) and 18\% worked from home occasionally (less than 4 days per year). $50 \%$ of participants never worked from home prior to lockdown. By Wave two, a dramatic shift to homeworking had occurred, with $74 \%$ per cent of our sample homeworking full-time and $3 \%$ part-time. $23 \%$ continued to work from their pre-COVID-19 location.

In line with recent research (e.g. Adams-Prassl et al., 2020), workers with high monthly salaries (> $£ 3,000$ per month) were more likely to be working from home ( $86 \%$ v $72 \% ; p=.014)$, as were university graduates $(82 \%$ v $59 \%, p<.001)$.

Table 1: Sample Personal Characteristics

\% / MEAN (SE)

$(N=610-621)$

\section{Gender}

Female

$63.9 \%$

Male / Other

$34.1 \%$

\section{Citizenship}

British

$93.7 \%$

Northern Irish

$1.9 \%$

Irish

$1.5 \%$

Other

$2.9 \%$

Ethnicity

White

Asian

Black

Other

$0.4 \%$

\section{Relationship Status}

Single / Divorced / Widowed $25.6 \%$

In a relationship / Married

\section{Education}

No Formal Education / Lower Secondary 
Cert / Diploma

Technical / Vocational

$10.6 \%$

Undergraduate

$41.6 \%$

Postgraduate

$21.1 \%$

Age

$38.3(.392)$

Parental Status

Parent

$50.2 \%$

Non-Parent

$49.8 \%$

Living on their own

Yes

$13.1 \%$

No

$86.9 \%$

Living with children

Yes

$52.2 \%$

No

$47.8 \%$

Net Monthly Household Income

$<£ 1,000$

$1.5 \%$

$£ 1,000-£ 2,000$

$25.4 \%$

$£ 2,000-£ 3,000$

$30.8 \%$

$£ 3,000-£ 4,000$

$32.6 \%$

$£ 4,000-£ 5,000$

$8.2 \%$

$>£ 5,000$

$1.5 \%$

Physical Health ( 1 = "Very Bad"; 5 = "Very Good")

“Good" (53.4\%)

Mental Health ( 1 = "Very Bad"; 5 = "Very Good")

"Good" (40.9\%)

Physical Health condition (Wave 1 only)

Yes

$23.1 \%$

No

$76.9 \%$

Mental Health condition (Wave 1 only)

Yes

$23.6 \%$

No

$76.4 \%$ 
Table 2: Sample Work Characteristics

\% / MEAN (SE)

$(N=610-621)$

\section{Contract type}

Permanent

$95.6 \%$

Temporary / Fixed-Term / Other

$4.4 \%$

Seniority ( $0=$ “Most Junior”, 5 = “Most Senior”)

\section{Tenure}

$<12$ months

$12.1 \%$

1-2 years

$11.3 \%$

Years $27.2 \%$

5-10 years $22.7 \%$

$>10$ years

Net Monthly Salary

$<£ 1,000$

$£ 1,000-£ 2,000$ $52.6 \%$

$£ 2,000-£ 3,000$ $30.1 \%$

$£ 3,000-£ 4,000$

$8.7 \%$

$>£ 4,000$

$4.4 \%$

\section{Sector}

Private

$60.3 \%$

Public

$39.7 \%$

\section{Industry}

Admin, IT \& Telecoms

Agriculture / Forestry / Fishing

$0.5 \%$

Arts / Entertainment

$0.8 \%$

Construction

$3.1 \%$

Education and Childcare

$14.3 \%$

Finance and Insurance

$9.1 \%$

Food

$2.4 \%$

Healthcare

$10.6 \%$

Manufacturing

$9.7 \%$ 
$\begin{array}{ll}\text { Other Services } & 3.2 \%\end{array}$

$\begin{array}{ll}\text { Professional Services } & 8.9 \%\end{array}$

$\begin{array}{ll}\text { Publishing / Media } & 1.8 \%\end{array}$

$\begin{array}{ll}\text { Retail } & 8.8 \%\end{array}$

Social Services \& Law Enforcement $\quad 4.4 \%$

$\begin{array}{ll}\text { Tourism } & 1.6 \%\end{array}$

$\begin{array}{ll}\text { Transportation } & 2.8 \%\end{array}$

$\begin{array}{ll}\text { Utilities } & 2.3 \%\end{array}$

Wholesale and Warehousing $\quad 1.5 \%$

\section{Organisation Size}

Micro ( $<10$ employees $) \quad 3.7 \%$

$\begin{array}{ll}\text { Small }(<50) & 12.0 \%\end{array}$

Medium $(<250) \quad 19.0 \%$

$\begin{array}{ll}\text { Large (> 250) } & 63.7 \%\end{array}$

Other $0.1 \%$

\subsection{Measures}

We employ 16 outcome variables to estimate the effect of COVID-19 and the associated restrictions on worker well-being and performance. All but two of the outcome variables contain ten or less missing observations. ${ }^{13}$ A full description of all variables is provided in $\underline{\mathrm{S}}$.

Life satisfaction is a global evaluative judgement made by an individual about the overall state of her life using a 0-10 scale. An identical format is used to measure workers' satisfaction with their homelife and jobs (job satisfaction). Single-item measures have been shown to correlate highly with longer life-satisfaction scales (Cheung and Lucas, 2014). ${ }^{14}$

\footnotetext{
${ }^{13}$ Experiential positive and negative affect contain twenty-seven missing observations each.

${ }^{14}$ As a robustness check we also use the Abridged Job Descriptive Index (AJDI) (Stanton et al, 2002) given evidence that multi-faceted domain measures may capture job satisfaction more completely.
} 
Global positive and negative affect are measured using the Institute of Work Psychology (IWP) Multiaffect Indicator (Warr and Parker, 2010; 2016). Respondents indicate the extent to which they experienced 16 emotions ( 8 negative, 8 positive) at work during the past month $(0=$ "Never" and $6=$ "Always"). Emotions are evenly split between high activation emotions (e.g. "excited"; "nervous") and low activation emotions (e.g. "calm"; "depressed"). Positive global affect is the mean of the 8 positive feeling scores and negative global affect is the mean of the 8 negative feelings scores. ${ }^{15}$ Cronbach's alpha scores for baseline and follow-up positive and negative affect are $.894 / .903$ and $.926 / .923$ respectively.

Experiential positive and negative affect are measured using the Day Reconstruction Method (DRM) (Kahneman et al, 1994). Workers use diaries to 'reconstruct' 3 consecutive 'episodes' from the previous working day. The time-of-day starting point for the episodes is randomly generated. Participants are asked when each episode started and ended; where they were; who they were with and what they were doing. They then rate the extent to which they experienced 16 feelings (the same used to measure global affect) during this episode, where 0 $=$ "Did not experience that feeling at all" and $6=$ "That feeling was an important part of the experience". Average positive and negative experiential affect are the mean positive and negative scores for the 3 combined episodes, with observations containing missing values excluded. ${ }^{16}$ Cronbach's alpha scores for baseline / follow-up positive and negative experiential affect are $.757 / .910$ and $.841 / .845$ respectively.

Organisational affective commitment, the extent to which workers feel emotionally attached to their organisations, is measured using Meyer and Allen's (1997) 6-item Affective Commitment Scale. Workers rate their agreement with 6 statements (3 positive, 3 negative) e.g. "I do not feel like 'part of the family' at my organization", where 1 = "Strongly Agree";

\footnotetext{
${ }^{15}$ For ease of comparison with the other affective measures used in this study, scores are recoded using a 0-6 scale and reverse cocding is not employed.

${ }^{16}$ Eight observations are omitted from Wave1 and nineteen from Wave 2.
} 
$5=$ "Strongly Disagree". Average commitment is the mean of the 6 scores, with reverse scoring applied to negative items. Cronbach's alpha are $.886 / .895$ (baseline / follow-up). Workers also rate their current levels of work-related stress (1= "Not at all Stressful"; 5= "Extremely Stressful") and indicate what aspects of working life they find most stressful.

Disengagement and exhaustion are measured using Demerouti and Bakker's (2008) previously validated ${ }^{17}$ 16-item Oldenburg-Burnout Inventory (OLBI). Respondents use a 14 scale to rate their level of agreement with 8 negative and 8 positive statements e.g. "During my work, I often feel emotionally drained”. Cronbach's alpha is .898/.894 (baseline / followup). The extent to which workers' needs for relatedness (feeling connected to people at work), competence (feeling capable of attaining desired work-related outcomes) and autonomy (feeling that work is compatible with self-identity) are met at work is assessed using the 21item Basic Psychological Needs Satisfaction at Work Scale (Deci et al, 2001). Respondents use a 1-7 scale to rank the trueness of statements e.g. "I really like the people I work with". Cronbach's alpha ranges from .873/.874 (relatedness) to .728/.703 (competence) and .678/.659 (autonomy). Workers also use a 1-5 scale to rate their general mental health (1= "Very Bad"; 5 = "Very good"). Finally, workers use the previously validated ${ }^{18}$ WHO HPQ measure (Kessler et al., 2003) to self-rate their overall job performance over the previous month relative to the worst and best job performance anyone could have at their job $(0=$ "Worst Performance"; $10=$ “Top Performance”).

\subsection{Data Analysis}

Using an approach similar to Pierce et al. (2020), we estimate changes in the well-being of worker $i$ at time $t\left(W W B_{i t}\right)$ during the period of COVID-19 restrictions using the equation:

\footnotetext{
${ }^{17}$ e.g. Halbesleben and Demerouti (2005)

18 E.g. Scuffham, Vecchio and Whiteford (2014); Previous worker well-being studies e.g. Jones, Molitor and Reif (2019) find a high correlation between self-rated and objective performance measures.
} 


$$
W W B_{i t}=\beta_{0}+\beta_{1} \text { ave }_{i}+u_{i}+\varepsilon_{i t}(1)
$$

where $\beta_{0}$ is the intercept which is assumed to be time-invariant and correlated with observed explanatory variables; wave $_{i}$ is a dummy variable that takes the value 1 for Wave 2 (May-June 2020) and 0 for Wave 1 (Nov 2019 - February 2020); $u_{i}$ captures the individual fixed effects; and $\varepsilon_{i t}$ denotes independent and identically distributed time-varying random shocks. The parameter $\beta_{1}$ captures the baseline difference in $\mathrm{WWB}_{\mathrm{i}}$ between Wave 1 (pre-restrictions) and Wave 2 (during-restrictions). A fixed effects model is appropriate given the high probability of unobserved characteristics confounding the relationship between COVID-19 restrictions and well-being (e.g. personality characteristics or gender differences in the division of childcare). The disadvantage of this approach is that time-invariant covariates commonly featured in wellbeing studies (e.g. gender and education) cannot be explicitly modelled as they do not change substantially over time. The main analysis is re-estimated using mixed and random effects models in $\underline{\mathrm{S} 7}$ and no material differences are found.

We first estimate within-person changes in well-being between Wave 1 and Wave 2. We then conduct sub-group analyses to examine heterogeneity in how homeworkers / nonhomeworkers and male / female homeworkers experience lockdown. Homeworkers (coded 1) are workers who are working from home (either full-time or most of the time) during Wave 2. Whether or not the homeworkers have switched to homeworking due to COVID-19 or have previous experience of homeworking is assumed to be picked up by the individual fixed effects. Non-homeworkers (coded 0) comprise workers who continue to work from their pre-lockdown location.

The outcomes are measured using ordinal scales but are treated as cardinal in line with the generally accepted approach to measuring subjective well-being in the empirical literature which assumes that Likert scales may be treated as continuous once individual fixed effects are 
accounted for. ${ }^{19}$ Robust standard errors, clustered at the individual level, are employed throughout in accordance with Moulton (1990).

The Benjamini-Hochberg (1995) method is used to control the false discovery rate (the proportion of significant results that represent false positives). P-values controlling for multiple testing are generated as follows: (1) The p-values from the 48 tests conducted for the primary analyses are ranked from smallest to largest, (2) each p-value is compared to a critical value $\left([i / m]^{*} Q\right)$, where $i$ is the rank, $m$ the total number of tests, and $Q$ is the false discovery rate of $0.05,(3)$ p-values are deemed significant if they are smaller than the p-value BenjaminiHochberg critical value at the relevant threshold (i.e. $\mathrm{p}<.05, \mathrm{p}<.01$, and $\mathrm{p}<.001$ ).

\section{RESULTS}

\subsection{Longitudinal Change in Worker-Wellbeing}

Bivariate correlations between the dependent variables are presented in $\underline{\mathrm{S} 4}$. Differences in the raw and standardised means and the results of paired-sample t-tests which examine differences in within-person well-being changes between homeworkers and non-homeworkers. are presented in $\underline{\mathrm{S} 5-\mathrm{S} 6}$. The raw means for the whole sample and by homeworking status are presented in Table 3.

These descriptives suggest that, overall, worker well-being is not adversely affected by the COVID-19 restriction, however, there is considerable heterogeneity. The fixed effects models which are summarised in Table 3 formally test these relationships.

\footnotetext{
${ }^{19}$ Ferrer -i Carbonell and Frijters (2004) show that results are not sensitive to the choice of OLS method - a finding replicated in several studies. Recent COVID-19 studies treat well-being cardinally (e.g. Zacher and Rudolph, 2020). Furthermore Baetschman, Staub and Winkelmann (2015 p.685) point out that "there is no consensus in the past literature on how to implement a fixed effects estimator for the ordered logit model". We estimate Equation 1 using an ordered logit fixed effects model in S14 and find no material change in the results.
} 
Table 3. Descriptives - Mean Outcomes by Homeworking Status ${ }^{++}$

\begin{tabular}{|c|c|c|c|c|c|c|}
\hline Outcome & $\begin{array}{c}\text { Wave1 } \\
\text { WS }^{+}\end{array}$ & $\begin{array}{l}\text { Wave2 } \\
\text { WS }\end{array}$ & $\begin{array}{l}\text { Wave } 1 \\
\text { NHW }\end{array}$ & $\begin{array}{l}\text { Wave } 2 \\
\text { NHW }\end{array}$ & $\begin{array}{c}\text { Wave 1 } \\
\text { HW }\end{array}$ & $\begin{array}{c}\text { Wave } 2 \\
\text { HW }\end{array}$ \\
\hline \multicolumn{7}{|l|}{$\underline{\text { Cognitive Well-being }}$} \\
\hline $\begin{array}{l}\text { Life Satisfaction } \\
(0-10)\end{array}$ & $\begin{array}{l}6.628 \\
(.073)\end{array}$ & $\begin{array}{l}6.562 \\
(.075)\end{array}$ & $\begin{array}{l}6.457 \\
(.176)\end{array}$ & $\begin{array}{l}6.357 \\
(.170)\end{array}$ & $\begin{array}{l}6.676 \\
(.079)\end{array}$ & $\begin{array}{l}6.614 \\
(.083)\end{array}$ \\
\hline $\begin{array}{l}\text { Homelife Satisfaction } \\
(0-10)\end{array}$ & $\begin{array}{l}7.173 \\
(.082)\end{array}$ & $\begin{array}{l}6.952 \\
(.082)\end{array}$ & $\begin{array}{l}6.986 \\
(.210)\end{array}$ & $\begin{array}{l}6.793 \\
(.192)\end{array}$ & $\begin{array}{l}7.226 \\
(.087)\end{array}$ & $\begin{array}{l}6.998 \\
(.091)\end{array}$ \\
\hline $\begin{array}{l}\text { Job Satisfaction } \\
(0-10)\end{array}$ & $\begin{array}{l}5.979 \\
(.087)\end{array}$ & $\begin{array}{l}6.109 \\
(.089)\end{array}$ & $\begin{array}{l}5.841 \\
(.193)\end{array}$ & $\begin{array}{l}5.813 \\
(.205)\end{array}$ & $\begin{array}{l}6.019 \\
(.097)\end{array}$ & $\begin{array}{l}6.192 \\
(.098)\end{array}$ \\
\hline \multicolumn{7}{|l|}{ Emotional Well-being } \\
\hline $\begin{array}{l}\text { Experiential Positive Affect } \\
(0-6)\end{array}$ & $\begin{array}{l}2.907 \\
(.037)\end{array}$ & $\begin{array}{l}2.971 \\
(.040)\end{array}$ & $\begin{array}{l}2.813 \\
(.083)\end{array}$ & $\begin{array}{l}2.877 \\
(.094)\end{array}$ & $\begin{array}{l}2.930 \\
(.041)\end{array}$ & $\begin{array}{l}2.992 \\
(.044)\end{array}$ \\
\hline $\begin{array}{l}\text { Experiential Negative Affect } \\
(0-6)\end{array}$ & $\begin{array}{l}2.111 \\
(.031)\end{array}$ & $\begin{array}{l}2.001 \\
(.028)\end{array}$ & $\begin{array}{l}2.037 \\
(.061)\end{array}$ & $\begin{array}{l}2.123 \\
(.060)\end{array}$ & $\begin{array}{l}2.134 \\
(.036)\end{array}$ & $\begin{array}{l}1.973 \\
(.032)\end{array}$ \\
\hline $\begin{array}{l}\text { Global Positive Affect } \\
(0-6)\end{array}$ & $\begin{array}{l}2.552 \\
(.043)\end{array}$ & $\begin{array}{l}2.530 \\
(.045)\end{array}$ & $\begin{array}{l}2.533 \\
(.092)\end{array}$ & $\begin{array}{l}2.522 \\
(.101)\end{array}$ & $\begin{array}{l}2.553 \\
(.049)\end{array}$ & $\begin{array}{l}2.530 \\
(.051)\end{array}$ \\
\hline $\begin{array}{l}\text { Global Negative Affect } \\
(0-6)\end{array}$ & $\begin{array}{l}1.558 \\
(.046)\end{array}$ & $\begin{array}{l}1.504 \\
(.046)\end{array}$ & $\begin{array}{l}1.552 \\
(.096)\end{array}$ & $\begin{array}{l}1.482 \\
(.104)\end{array}$ & $\begin{array}{l}1.564 \\
(.053)\end{array}$ & $\begin{array}{l}1.513 \\
(.052)\end{array}$ \\
\hline $\begin{array}{l}\text { Affective Commitment } \\
(1-5)\end{array}$ & $\begin{array}{l}2.982 \\
(.040)\end{array}$ & $\begin{array}{l}3.170 \\
(.040)\end{array}$ & $\begin{array}{l}2.900 \\
(.085)\end{array}$ & $\begin{array}{l}3.042 \\
(.087)\end{array}$ & $\begin{array}{l}3.008 \\
(.046)\end{array}$ & $\begin{array}{l}3.211 \\
(.046)\end{array}$ \\
\hline \multicolumn{7}{|l|}{ Psychological Well-being } \\
\hline $\begin{array}{l}\text { Work Stress } \\
(1-5)\end{array}$ & $\begin{array}{l}3.080 \\
(.041)\end{array}$ & $\begin{array}{l}3.066 \\
(.041)\end{array}$ & $\begin{array}{l}3.124 \\
(.091)\end{array}$ & $\begin{array}{l}3.081 \\
(.090)\end{array}$ & $\begin{array}{l}3.073 \\
(.046)\end{array}$ & $\begin{array}{l}3.070 \\
(.046)\end{array}$ \\
\hline $\begin{array}{l}\text { Disengagement } \\
(1-4)\end{array}$ & $\begin{array}{l}2.470 \\
(.022)\end{array}$ & $\begin{array}{l}2.389 \\
(.022)\end{array}$ & $\begin{array}{l}2.571 \\
(.050)\end{array}$ & $\begin{array}{l}2.486 \\
(.050)\end{array}$ & $\begin{array}{l}2.440 \\
(.025)\end{array}$ & $\begin{array}{l}2.360 \\
(.025)\end{array}$ \\
\hline $\begin{array}{l}\text { Exhaustion } \\
(1-4)\end{array}$ & $\begin{array}{l}2.535 \\
(.022)\end{array}$ & $\begin{array}{l}2.425 \\
(.021)\end{array}$ & $\begin{array}{l}2.667 \\
(.042)\end{array}$ & $\begin{array}{l}2.541 \\
(.047)\end{array}$ & $\begin{array}{l}2.499 \\
(.026)\end{array}$ & $\begin{array}{l}2.393 \\
(.024)\end{array}$ \\
\hline $\begin{array}{l}\text { Relatedness } \\
(1-7)\end{array}$ & $\begin{array}{l}4.953 \\
(.043)\end{array}$ & $\begin{array}{l}5.014 \\
(.040)\end{array}$ & $\begin{array}{l}4.912 \\
(.091)\end{array}$ & $\begin{array}{l}4.969 \\
(.088)\end{array}$ & $\begin{array}{l}4.961 \\
(.049)\end{array}$ & $\begin{array}{l}5.023 \\
(.046)\end{array}$ \\
\hline $\begin{array}{l}\text { Competence } \\
(1-7)\end{array}$ & $\begin{array}{l}4.973 \\
(.041)\end{array}$ & $\begin{array}{l}5.046 \\
(.038)\end{array}$ & $\begin{array}{l}5.026 \\
(.081)\end{array}$ & $\begin{array}{l}5.069 \\
(.081)\end{array}$ & $\begin{array}{l}4.955 \\
(.048)\end{array}$ & $\begin{array}{l}5.037 \\
(.044)\end{array}$ \\
\hline $\begin{array}{l}\text { Autonomy } \\
(1-7)\end{array}$ & $\begin{array}{l}4.421 \\
(.044)\end{array}$ & $\begin{array}{l}4.538 \\
(.040)\end{array}$ & $\begin{array}{l}4.280 \\
(.089)\end{array}$ & $\begin{array}{l}4.378 \\
(.088)\end{array}$ & $\begin{array}{l}4.460 \\
(.050)\end{array}$ & $\begin{array}{l}4.588 \\
(.045)\end{array}$ \\
\hline $\begin{array}{l}\text { Mental Health } \\
(1-5)\end{array}$ & $\begin{array}{l}3.614 \\
(.036)\end{array}$ & $\begin{array}{l}3.639 \\
(.035)\end{array}$ & $\begin{array}{l}3.489 \\
(.083)\end{array}$ & $\begin{array}{l}3.621 \\
(.080)\end{array}$ & $\begin{array}{l}3.643 \\
(.039)\end{array}$ & $\begin{array}{l}3.643 \\
(.039)\end{array}$ \\
\hline \multicolumn{7}{|l|}{$\underline{\text { Performance }}$} \\
\hline $\begin{array}{l}\text { Self-rated Performance } \\
(0-10)\end{array}$ & $\begin{array}{l}7.612 \\
(.058)\end{array}$ & $\begin{array}{l}7.107 \\
(.070)\end{array}$ & $\begin{array}{l}7.633 \\
(.126)\end{array}$ & $\begin{array}{l}7.511 \\
(.142)\end{array}$ & $\begin{array}{l}7.604 \\
(.066)\end{array}$ & $\begin{array}{l}6.992 \\
(.080)\end{array}$ \\
\hline
\end{tabular}

$+W S=$ Whole Sample $;$ NHW= Non-Homeworkers $; H W=$ Homeworkers ++ Standard errors in parentheses 


\section{Fixed Effects Model of Within Worker Changes in Well-being and Job Performance}

A linear fixed-effect model is estimated to examine changes in within-worker well-being during the period of COVID-19 restrictions. Equation 1 is estimated using OLS, where $W W B_{i t}$ corresponds to one of 16 outcomes (15 well-being outcomes and self-rated performance) and $\beta_{1}$ captures the change in $W W B_{i}$ associated with moving from Wave1 to Wave2.

The main effect for each outcome is presented in Table 4. Column two summarises the changes in well-being for the whole sample. Overall, the impact of the COVID-19 restrictions is positive, with several measures of affective and psychological work-related well-being significantly improving. Workers feel more emotionally attached to their organisations $(+.18$ sd; CI [.124 - .246]; $p<.001$ ) and experience fewer negative emotions the previous working day (-.15 sd; [CI [-.254 - -.046]; $p=.013)$. The risk of burnout also decreases, as evidenced by significant reductions in disengagement (-.14 sd; (CI [-.202- -.079]; $p<.001)$ and exhaustion ($.19 \mathrm{sd} ; \mathrm{CI}[-.256--.141] ; p<.001)$.

In addition, the extent to which workers feel that their basic psychological needs are being met at work increases, with workers reporting significant rises in relatedness $(+.06 \mathrm{sd}$; CI [.027 - .088]; $p<.001)$, competence (+.07 sd; CI [.033 - .112]; $p<.001)$ and autonomy $(.11$ sd; CI [.067-.152]; $p<.001)$.

At the same time, homelife satisfaction deteriorates significantly (-.11 sd; CI [-.178 - $.038] ; p=.009)$, as does self-rated job performance (-.31 sd; CI [ -.398 - -.223]; p<.001). However, the COVID-19 restrictions are not associated with significant changes in life or job satisfaction, mental health, positive global or experiential affect, experiential negative affect or stress. 
Table 4. Fixed Effects -Standardised Main Effects by Homeworking Status

\begin{tabular}{|c|c|c|c|}
\hline Outcomes & $\begin{array}{c}\text { Whole Sample } \\
\text { Coefficient } \\
\text { (SD change) }\end{array}$ & $\begin{array}{c}\text { Non-Homeworkers } \\
\text { Coefficient } \\
\text { (SD change) }\end{array}$ & $\begin{array}{c}\text { Homeworkers } \\
\text { Coefficient } \\
\text { (SD change) }\end{array}$ \\
\hline \multicolumn{4}{|l|}{ Cognitive well-being } \\
\hline Life Satisfaction & $\begin{array}{l}-.035 \\
(.036)\end{array}$ & $\begin{array}{l}-.054 \\
(.085)\end{array}$ & $\begin{array}{l}-.034 \\
(.039)\end{array}$ \\
\hline Homelife Satisfaction & $\begin{array}{c}-.108^{* * *} \\
(035)\end{array}$ & $\begin{array}{l}-.093 \\
(.086)\end{array}$ & $\begin{array}{l}-.111^{*} \\
(.039)\end{array}$ \\
\hline Job Satisfaction & $\begin{array}{c}.059 \\
(.036)\end{array}$ & $\begin{array}{l}-.013 \\
(.094)\end{array}$ & $\begin{array}{c}.078 \\
(.039)\end{array}$ \\
\hline \multicolumn{4}{|l|}{ Emotional well-being } \\
\hline Global Positive Affect & $\begin{array}{l}-.020 \\
(.035)\end{array}$ & $\begin{array}{l}-.089 \\
(.081)\end{array}$ & $\begin{array}{l}-.020 \\
(.038)\end{array}$ \\
\hline Global Negative Affect & $\begin{array}{l}-.046 \\
(.031)\end{array}$ & $\begin{array}{l}-.061 \\
(.064)\end{array}$ & $\begin{array}{l}-.044 \\
(.036)\end{array}$ \\
\hline Experiential positive affect & $\begin{array}{c}.066 \\
(.042)\end{array}$ & $\begin{array}{c}.067 \\
(.092)\end{array}$ & $\begin{array}{c}.064 \\
(.048)\end{array}$ \\
\hline Experiential negative affect & $\begin{array}{l}-.150^{*} \\
(.053)\end{array}$ & $\begin{array}{l}.116 \\
(.105)\end{array}$ & $\begin{array}{c}-.219^{* * * *} \\
(.060)\end{array}$ \\
\hline Affective Commitment & $\begin{array}{l}.185^{* * * *} \\
(.031)\end{array}$ & $\begin{array}{l}.140 \\
(.063)\end{array}$ & $\begin{array}{l}.199^{\text {**** }} \\
(.035)\end{array}$ \\
\hline \multicolumn{4}{|l|}{ Psychological well-being } \\
\hline Work Stress & $\begin{array}{l}-.014 \\
(.032)\end{array}$ & $\begin{array}{l}-.042 \\
(.076)\end{array}$ & $\begin{array}{l}-.002 \\
(.035)\end{array}$ \\
\hline Disengagement & $\begin{array}{l}-.141^{* * * * *} \\
(.031)\end{array}$ & $\begin{array}{l}-.150 \\
(.068)\end{array}$ & $\begin{array}{c}-.140^{* * * *} \\
(.035)\end{array}$ \\
\hline Exhaustion & $\begin{array}{l}-.199^{* * * *} \\
(.029)\end{array}$ & $\begin{array}{l}-.226^{* *} \\
(.063)\end{array}$ & $\begin{array}{c}-.191^{\text {***** }} \\
(.033)\end{array}$ \\
\hline Relatedness & $\begin{array}{l}.057^{* * * *} \\
(.015)\end{array}$ & $\begin{array}{c}.054 \\
(.035)\end{array}$ & $\begin{array}{l}.059^{* * *} \\
(.017)\end{array}$ \\
\hline Competence & $\begin{array}{l}.073^{* * * *} \\
(.020)\end{array}$ & $\begin{array}{l}.042 \\
(.041)\end{array}$ & $\begin{array}{l}.082^{* * * *} \\
(.022)\end{array}$ \\
\hline Autonomy & $\begin{array}{l}.109^{* * * *} \\
(.021)\end{array}$ & $\begin{array}{l}.093 \\
(.048)\end{array}$ & $\begin{array}{l}.121^{* * * *} \\
(.023)\end{array}$ \\
\hline Mental Health & $\begin{array}{l}.029 \\
(.034)\end{array}$ & $\begin{array}{l}.148 \\
(.074)\end{array}$ & $\begin{array}{l}-.001 \\
(.039)\end{array}$ \\
\hline Productivity & & & \\
\hline Self-rated Performance & $\begin{array}{c}-.311^{* * * *} \\
(.044) \\
\end{array}$ & $\begin{array}{l}-.075 \\
(.092) \\
\end{array}$ & $\begin{array}{c}-.378^{* * * *} \\
(.050) \\
\end{array}$ \\
\hline
\end{tabular}

$* * * p<0.001, * * p<0.01 * * p<0.05$. Adjusted $p$-values are significant at the threshold identified $(p<.05, p<.01, p<.001)$ after controlling for multiple testing (Benjamini-Hochberg procedure); Standardised variables. Robust clustered standard errors in parentheses 
Columns 3 and 4 in Table 4 suggest that these results are largely driven by homeworkers. Tables $\underline{\mathrm{S} 8}$ and $\underline{\mathrm{S} 9}$ depict a further sub-group analysis which decomposes the main effects by homeworking status and gender.

The homelife satisfaction of homeworkers decreases significantly (-.23 sd; CI [-..384 -.072]; $p=.011$ ) during lockdown, a reduction driven by females. While global positive and negative affect remain relatively stable for both groups, homeworkers report experiencing fewer negative emotions the previous working day (-.16 sd; CI [-.248 - -.073]; $p<.001)$, however no such effect is found for non-homeworkers. Analysing within-worker changes in individual emotions offers additional insights into the affective mechanisms which may be driving these results (see S10 - S13 for further detail). While non-homeworkers fail to report any significant changes in the extent to which they experienced positive or negative feelings the previous month, homeworkers report feeling significantly less enthusiastic (-.20 sd; CI[$.291--.117] ; p<.001)$ but also significantly less dejected (-.20 sd; CI [-.292 - -.117]; $p<.001)$. The reduction in experiential negative affect for homeworkers is driven by significant decreases in the extent to which they report feeling tense (-.20 sd; CI [-.325- -.076]; $p=.048)$ and nervous (-.19 sd; CI [-.321 - -.075]; $p=.096)$ the previous working day.

Overall levels of work-related stress remain constant for both groups, although there is evidence of between-group differences in rankings of stressors pre-and during the period of restrictions. ${ }^{20}$ The COVID-19 restrictions are associated with an improvement in the psychological well-being of both groups, although the effects are stronger for homeworkers. In terms of burnout, both homeworkers (-.19 sd; CI [-.256--.125]; $p<.001)$ and non-homeworkers (-.23 sd; CI [-.351 - -..100]; $p=.003)$ report significantly lower levels of exhaustion. Both homeworkers (+.22 sd; CI [.143 - .299]; $p<.001)$ and non-homeworkers (+.22 sd; CI [.081 -

\footnotetext{
${ }^{20}$ Homeworkers are significantly less stressed by their clients, co-workers, deadlines and hours during lockdown but are more stressed by job security. They are just as stressed about achieving a good work-life balance as pre-COVID-19.
} 
.357]; $p=.005$ ) feel less tired before starting work and have more energy for leisure activities (homeworkers: -.22 sd; CI [-.311 - -.138]; $p<.001$; non-homeworkers: -.22 sd; CI [-.368 - .035]; $p=.034)$ ). In addition, homeworkers report a significant drop in disengagement (-.14 sd; CI $[-.209--.071] ; p<.001)$, driven by an increase in the extent to which they report feeling more engaged in their work (-.14 sd; CI [-.233 - -.047]; $p=.007)$ and less prone to performing their jobs "mechanically" $(+.10 \mathrm{sd}$; CI [.005 - .190]; $p=.064)$ or to talking about their work in a negative way (+.19 sd; CI [. $119-.279] ; p<.001)$.

Homeworkers' work-related psychological needs are better met during lockdown, with significant increases in relatedness (+.06 sd; CI [.024 - .093]: $p=.003)$, competence (+.08 sd; CI [.037 - .127]: $p<.001)$, and autonomy (+.12 sd; CI [.074 - .167]: $p<.001)$ reported. An analysis of sub-scale items reveals that the increase in competence relates to an increase in the extent to which homeworkers feel a sense of accomplishment $(+.26$ sd; CI [.181 - .335]; $p<.001)$. The increase in homeworkers' relatedness is driven by an increased sense of being part of a supportive work community, with homeworkers reporting an increase in the extent to which they like the people they work with $(+.14 \mathrm{sd}$; CI $[.065-.223] ; p<.001)$ and regard them as friends (+.10 sd; CI [.026 - .169]; $p=.029)$ who care about them $(+.15 \mathrm{sd}$; CI [.075 - .229]; $p<.001)$. The increase in homeworkers' autonomy score relates to an increase in the extent to which homeworkers feel free to express their opinions (+.15 sd; CI [.069 - .236]; $p<.001)$ and feel that their feelings are taken into consideration (+.30 sd; CI [.227- .380$] ; p<.001)$ at work. Homeworkers report significant increases in both affective commitment $(+.20 \mathrm{sd}$; CI $[.13-.27] ; p<.001)$ and the extent to which they feel that their organisations prioritise worker well-being $(+.27 \mathrm{sd}$; CI [.198 - .345]; $p<.001]$. Neither group reports a significant change in self-rated mental health. In terms of productivity, homeworkers report a significant 
deterioration in their self-rated performance (-.38 sd; CI [-.477- -.278]; $p<.001) .{ }^{21}$ This result holds for both male and female homeworkers, with similar effect sizes found for both groups.

\section{Discussion}

Our findings highlight the need for policymakers to consider individual differences when evaluating the impact of potential pandemic responses on well-being. In contrast to most COVID-19 well-being papers, our study of full-time workers demonstrates that lockdown should not necessarily be construed as a universally negative experience. We find evidence of considerable within-sample heterogeneity, with homeworkers' overall well-being improving during COVID-19 restrictions, due mainly to a reduction in experiential negative affect, an increase in autonomy and an increase in the extent to which they feel supported and cared for by their organisations.

In contrast to Zacher and Rudolph (2020), life satisfaction declines only marginally in our sample during lockdown. Similar to Moehring et al., (2020), we find a significant drop in the homelife satisfaction of homeworkers. In relation to emotional well-being, while overall global affect remains relatively stable, we find that experiential negative affect declines significantly for homeworkers, supporting the separability of global and experiential measures. Zacher and Rudolph (2020) find a similar decline in negative affect for homeworkers, a finding which they suggest may reflect an increase in low activation negative emotions, although they do not measure this. Our findings suggest otherwise. Other than dejection, lockdown is not associated with a significant decrease in low activation negative feelings experienced by homeworkers, raising the possibility that the decrease in negative affect revealed by both studies is not a measurement artefact but may instead reflect coping mechanisms, as

\footnotetext{
${ }^{21} 48 \%$ of homeworkers feel "less productive than normal due to COVID-19", versus 27\% of non-homeworkers (p<.001). $38 \%$ of homeworkers admit to getting less done when they work from home and 19\% admit to producing work of lower quality when they work from home. The three biggest reasons cited by homeworkers for getting less done is a lack of motivation; getting distracted easily and having a poor physical work set-up at home.
} 
hypothesised by Zacher and Rudolph (2020). Alternatively, it may reveal something fundamental about the lived reality of homeworking.

Experiential negative affect notwithstanding, the life satisfaction and overall happiness of full-time workers appear to be relatively unaffected by the COVID-19 restrictions. This may reflect low baseline scores ${ }^{22}$ or a data collection period which is too short to register significant changes in longer-term, global measures. Happiness at work is 'sticky' (Fisher, 2014) and highly dependent on stable dispositional traits. Sample composition is undoubtedly also a factor. We exclude workers who are no longer working due to the pandemic, thus eliminating one of the most severe COVID-19-related well-being shocks. An alternative explanation for our findings which is supported by recent research, is adaptation. Previous research on 'adaptive preferences' shows that individuals scale down their expectations to avoid disappointment when faced with adverse conditions (White, 2009). Workers may have already adapted to the initial shock of lockdown restrictions by Wave 2 and their well-being may have already reverted to its original 'set point' level (Lykken and Tellegen, 1996). Alternatively, workers' scores may incorporate an anticipatory element, reflecting their belief that, six weeks into lockdown, the worst of the pandemic is over.

To the best of our knowledge no studies to date have examined the impact of COVID19 restrictions on work-related psychological well-being. Our findings reveal that lockdowninduced homeworking is associated with positive changes in psychological well-being. Homeworkers feel more autonomous compared to their pre-pandemic levels. They report being able to express their opinions more freely. They also enjoy the positive challenge and opportunities for learning which a new way of working presents and feel a stronger sense of accomplishment. Somewhat counterintuitively, homeworkers' relatedness, a measure of the

\footnotetext{
${ }^{22}$ Average life satisfaction in the UK is 7.7 versus a baseline level of 6.6 in our sample. Layard et al (2020) also report a substantial decrease in life satisfaction in their UK sample prior to lockdown. Hudson, Lucas and Donnellan (2019) report average global positive and negative affect of approximately 4 and 2.5 respectively versus our baseline levels of 2.5 and 1.5.
} 
strength of their social ties and relationships with their work colleagues, improves significantly during COVID-19 restrictions. The individual scale items reveal that this is due to an enhanced sense of community. Homeworkers feel closer to and more friendly towards their colleagues than they did prior to COVID-19 and this is reciprocated, with homeworkers in turn feeling more cared for. This may explain why homeworkers report feeling more emotionally attached to their organisations compared to the pre-pandemic period. This enhanced sense of belonging is also reflected in a significant increase in the extent to which homeworkers believe that their organisations prioritise worker well-being, highlighting the link between organisational support and positive homeworking experiences previously documented by Allen (2001). Our results also reveal a significant reduction in burnout symptoms during COVID-19. Both homeworkers and non-homeworkers report feeling significantly more energised at work and having more energy for leisure activities. In addition, homeworkers are significantly more engaged in their work and have a more positive attitude towards it. In contrast to other COVID19 studies, we find no evidence of a deterioration in mental health. This may reflect sample composition (e.g. a low proportion of young adults and less educated workers) or adaptation.

While our results reveal a generally positive association between COVID-19 restrictions and homeworkers' well-being, there is evidence that this may be at the expense of productivity. While other studies report improvements in homeworkers' performance during lockdown (e.g. Baudot et al, 2020), our results reveal a significant negative association between homeworking and self-rated performance. It is unlikely that this decrease is purely related to group composition effects. ${ }^{23}$ It may partially reflect a 'COVID-19 effect'. ${ }^{24}$ It may also reflect the suddenness of the switch to homeworking and a general lack of preparedness for homeworking. The decline in performance may also reflect the largely involuntary nature of the switch to homeworking. Alternatively, the fall in performance may reflect reduced work

\footnotetext{
${ }^{23}$ Homeworkers and non-homeworkers have similar baseline performance and rates of promotion / pay rises.

${ }^{24} 48 \%$ of homeworkers report" feeling less productive at work than usual due to COVID-19" versus $27 \%$ of non-homeworkers.
} 
effort on the part of homeworkers. Homeworkers report working on average 19 hours less during the period of COVID-19 restrictions, despite an average reduction in their weekly contractual hours of just two hours. It is not clear whether this reduction is due to reduced demands on the part of their employers or whether it relates to a lack of motivation and/or ability on homeworkers' part to successfully navigate an entirely new way of working, for which they may be ill-equipped cognitively or emotionally. ${ }^{25}$

Our study has some limitations which could be addressed by future research. The first area of potential concern relates to the selective nature of our sample. While the evidence that 'professional' survey participants differ demographically and attitudinally from other survey participants is mixed, our participants may differ systematically from the 'average' worker. ${ }^{26}$ For example, workers who can work from home may be overrepresented in online surveys (Dingel and Neiman, 2020). In addition, while our sample is by design restricted to full-time workers, female, middle-aged and highly educated workers are over-represented, which may detract from the wider generalisability of our results. An obvious direction for future research would be to target a more ethnically and socioeconomically diverse online sample and/or to extend our survey to a field setting.

A second issue relates to timing. The time intervals between waves are not constant across individuals. However, robustness tests reveal that the wave variable picks up most of this variation, rendering the inclusion of a month variable inappropriate. Secondly, it is possible that our follow-up survey was issued too 'late' (e.g. workers may have already adapted and easing of lockdown had in some cases already commenced) or too 'early' (e.g only two people in our sample had been physically affected by the virus at the time of the second survey; and homeworkers may still have been in the 'honeymoon' phase, resulting in an under-reporting of some of the well-documented negative aspects of homeworking e.g. isolation). The study

\footnotetext{
${ }^{25} 26 \%$ of homeworkers report getting less work done at home due to a lack of motivation. $25 \%$ say it is due to getting distracted ${ }^{26}$ See Huff and Tingley (2015) and Hillygus, Jackson, and McKenzie Young (2014) for a summary.
} 
would benefit from the inclusion of additional waves of data to examine the longer-term impact of the pandemic and involuntary homeworking on well-being.

Thirdly, the use of a fixed effects model, while econometrically appropriate, eliminates potentially policy-relevant sources of heterogeneity such as personality, having a mental health condition etc. Future research could tease out the relationship between additional covariates and homeworking preferences and/or effectiveness. Finally, our outcome variables are subjective, self-rated scales, which may raise concerns about self-report and recall bias. While including additional time points would partially address this, combining objective measures of performance (e.g. supervisor ratings) with self-rated performance data, potentially within a field setting, would strengthen validity.

Our results provide a valuable insight into how policy responses to an exogenous shock can affect how individuals experience and evaluate their working lives. As Layard et al., (2020) point out, decisions around appropriate pandemic responses require high-quality information on the potential psychological and emotional cost for society. By utilising multiple measures to capture the lived reality of one such policy response (lockdown) for full-time workers and by demonstrating the considerable heterogeneity in experiences, our study makes a valuable contribution to this debate.

One by-product of the COVID-19 restrictions which is likely to have longevity is the global shift to homeworking. Our study is one of very few that captures the lived experience of homeworking and in particular, the lived experience of workers who may not otherwise have chosen to work from home. Our results suggest that homeworking benefits full-time workers through increased psychological well-being and fewer negative work-related emotions. However, these improvements are accompanied by reductions in homelife satisfaction and job performance. Whether this trade-off reflects the sudden, largely involuntary nature of the shift to homeworking or the extraordinary circumstances initiated by COVID-19 (e.g. school 
closures), or whether it is a feature of homeworking per se, is of direct economic relevance to organisations currently seeking to future-proof labour force deployment and real estate strategies. The direction in which the homeworking cost-benefit balance revealed by our results shifts post-pandemic will largely depend on the extent to which organisations are willing to consider individual preferences for homeworking. Whether or not the potential cost savings associated with homeworking justify encouraging employees who dislike homeworking, or who are ill-suited to it, to continue to work from home post-pandemic is an important policy question which warrants further investigation. 


\section{REFERENCES}

Adams-Prassl, Abi, Teodora Boneva, Marta Golin and Christopher Rauh. 2020. "Inequality in the impact of the coronavirus shock: Evidence from real time surveys.". IZA Institute of Labour Economics Working Paper DP No. 13183

Allen, Tammy D. 2001. "Family-supportive work environments: The role of organizational perceptions." Journal of Vocational Behavior 58(3): 414-435

Anderson, Deirdre and Clare Kelliher. 2009. "Flexible working and engagement: The importance of choice." Strategic HR Review 8(2): 13-18(6)

Baert, Stijn, Louis Lippens, Eline Moens, Johannes Weytjens and Philippe Sterkens. 2020. "The COVID-19 crisis and telework: A research survey on experiences, expectations and hopes". IZA Institute of Labour Economics Working Paper DP No. 13229

Baetschmann, Gregori, Kevin E. Staub and Rainer Winkelmann. 2015. "Consistent estimation of the fixed effects ordered logit model." Journal of the Royal Statistical Society. Series A (Statistics in Society): 685-703.

Bakker, Arnold B. and Evangelia Demerouti. 2008. "Towards a model of work engagement." Career development international 13(3): 209-223.

Bakker, Arnold B. and Wido Oerlemans. 2011. "Subjective well-being in organizations." The Oxford handbook of positive organizational scholarship 49:178-189.

Baudot, Lisa and Khim Kelly. 2020. "A Survey of Perceptions of Remote Work and Work Productivity in the United States during the COVID-19 Shutdown." University of Central Florida Working Paper. Available at SSRN 3646406 
Beland, Louis-Philippe, Abel Brodeur, Joanne Haddad and Derek Mikola. 2020. Covid-19, family stress and domestic violence: Remote work, isolation and bargaining power. GLO Discussion Paper No. 571.

Bell, David NF, and David G. Blanchflower. 2020. "US and UK labour markets before and during the Covid-19 crash." National Institute Economic Review 252: R52-R69.

Berlemann, Michael. 2016. "Does hurricane risk affect individual well-being? Empirical evidence on the indirect effects of natural disasters." Ecological Economics 124: 99-113.

Binnewies, Carmen, Sabine Sonnentag and Eva J. Mojza. 2009. "Feeling recovered and thinking about the good sides of one's work." Journal of Occupational Health Psychology 14(3): 243.

Bloom, Nicholas, James Liang, John Roberts and Zhichun Jenny Ying. 2015. "Does working from home work? Evidence from a Chinese experiment." The Quarterly Journal of Economics 130, 1: 165-218.

Caesens, Gaëtane, Florence Stinglhamber and Virginie Marmier. 2016. "The curvilinear effect of work engagement on employees' turnover intentions." International Journal of Psychology 51(2): 150-155.

Canonico, Esther. 2016. "Putting the work-life interface into a temporal context: an empirical study of work-life balance by life stage and the consequences of homeworking." $\mathrm{PhD}$ diss., London School of Economics and Political Science (LSE)

Cabarkapa, Sonja., Sarah Nadjidai, Jerome Murgier and Chee Ng. 2020. The psychological impact of COVID-19 and other viral epidemics on frontline healthcare workers and ways to address it: A rapid systematic review. Brain, Behavior, \& Immunity, 8: 100-144. 
Charalampous, Maria, Christine A. Grant, Carlo Tramontano and Evie Michailidis. 2019. "Systematically reviewing remote e-workers' well-being at work: a multidimensional approach." European Journal of Work and Organizational Psychology 28, 1: 51-73.

Csikszentmihalyi, Mihaly and Mihaly Csikzentmihaly. 1990. Flow: The psychology of optimal experience. Vol. 1990. New York: Harper \& Row

Cheung, Felix and Richard E. Lucas. 2014. "Assessing the validity of single-item life satisfaction measures: Results from three large samples." Quality of Life research 23, 10: 28092818.

Daly, Michael. and Eric Robinson. 2020. Psychological distress and adaptation to the COVID-19 crisis in the United States. Journal of Psychiatric Research. doi.org/10.1016/j.jpsychires.2020.10.035

Daly, Michael., Angelina Sutin and Eric Robinson. 2020. Longitudinal changes in mental health and the COVID-19 pandemic: Evidence from the UK Household Longitudinal Study. Psychological Medicine: 1-37.

Deci, Edward L., Richard M. Ryan, Marylène Gagné, Dean R. Leone, Julian Usunov and Boyanka P. Kornazheva. 2001. "Need satisfaction, motivation, and well-being in the work organizations of a former eastern bloc country: A cross-cultural study of selfdetermination." Personality and social psychology bulletin 27(8): 930-942.

Demerouti, Evangelia, and Arnold B. Bakker. 2008. "The Oldenburg Burnout Inventory: A good alternative to measure burnout and engagement." Handbook of stress and burnout in health care: $65-78$.

DeSimone, Stefania. 2014. "Conceptualizing wellbeing in the workplace." International journal of business and social science 5(12) 
Dingel, Jonathan I. and Brent Neiman. 2020. How many jobs can be done at home?. NBER Working Paper No. 26948. Cambridge, MA: National Bureau of Economic Research

Diener, Ed, Martin EP Seligman, Hyewon Choi and Shigehiro Oishi. 2018. "Happiest people revisited." Perspectives on Psychological Science 13(2):176-184.

Fancourt, Daisy, Feifei Bu, Hei Wan Mak and Andrew Steptoe. 2020. "COVID-19 social study." Results release 15 (2020).

Fancourt, Daisy, Andrew Steptoe and Feifei Bu. 2020. "Trajectories of anxiety and depressive symptoms during enforced isolation due to COVID-19 in England: a longitudinal observational study." The Lancet Psychiatry; DOI:https://doi.org/10.1016/S2215-0366(20)30482-X

Felstead, Alan, and Darja Reuschke.2020. "Homeworking in the UK: before and during the 2020 lockdown."; WISERD Report, Cardiff: Wales Institute of Social and Economic Research and Data

Ferrer-i-Carbonell, Ada, and Paul Frijters. 2004. "How important is methodology for the estimates of the determinants of happiness?". The Economic Journal 114(497): 641-659.

Fisher, Cynthia D. "Conceptualizing and measuring wellbeing at work. 2014. " Wellbeing: A complete reference guide: 1-25.

Folkard, Simon and Philip Tucker. 2003. "Shift work, safety and productivity." Occupational medicine 53(2): 95-101.

Globig, Laura K., Bastien Blain and Tali Sharot. 2020. "When Private Optimism meets Public Despair: Dissociable effects on behavior and well-being." Pre-print psyarxiv.com DOI: $10.31234 /$ osf.io/gbdn8 
Halbesleben, Jonathon RB, and Evangelia Demerouti. 2005. "The construct validity of an alternative measure of burnout: Investigating the English translation of the Oldenburg Burnout Inventory." Work \& Stress 19(3): 208-220.

Hearn, Alex. 2020. http. "Covid-19 could cause permanent shift towards home working | Technology", The Guardian". 13 March,2020

Huebener, Mathias, C. Spiess, Nico Siegel, and Gert Wagner. 2020. "Parental well-being in times of Covid-19 in Germany." IZA Institute of Labour Economics Working Paper DP No. 13556

Hillygus, D. Sunshine, Natalie Jackson, and M. Young. 2014. "Professional respondents in non-probability online panels." Online panel research: A data quality perspective 1: 219-237.

Hudson, Nathan W., Richard E. Lucas, and M. Brent Donnellan. 2017. "Day-to-day affect is surprisingly stable: a 2-year longitudinal study of well-being." Social psychological and personality science 8(1): 45-54.

-. 2016. "Getting older, feeling less? A cross-sectional and longitudinal investigation of developmental patterns in experiential well-being." Psychology and Aging 31(8): 847.

-. 2019. "Healthier and happier? A 3-year longitudinal investigation of the prospective associations and concurrent changes in health and experiential well-being." Personality and Social Psychology Bulletin 45(12): 1635-1650.

Huff, Connor and Dustin Tingley. 2015. "“Who are these people?" Evaluating the demographic characteristics and political preferences of MTurk survey respondents." Research \& Politics 2(3) 
Jones, Damon, David Molitor and Julian Reif. 2019. "What do workplace wellness programs do? Evidence from the Illinois workplace wellness study." The Quarterly Journal of Economics 134(4): 1747-1791.

Kahneman, Daniel, Alan B. Krueger, David A. Schkade, Norbert Schwarz and Arthur A. Stone. 2004. "A survey method for characterizing daily life experience: The day reconstruction method." Science 306(5702): 1776-1780.

Kessler, Ronald C., Catherine Barber, Arne Beck, Patricia Berglund, Paul D. Cleary, David McKenas, Nico Pronk et al. 2003. "The world health organization health and work performance questionnaire (HPQ)." Journal of Occupational and Environmental Medicine 45(2): 156-174.

Lau, Anna LD, Iris Chi, Robert A. Cummins, Tatia MC Lee, Kee-L. Chou and Lawrence WM Chung. 2008. "The SARS (Severe Acute Respiratory Syndrome) pandemic in Hong Kong: Effects on the subjective wellbeing of elderly and younger people." Aging and mental health 12(6): 746-760.

Layard, Richard, Andrew Clark, Jan-Emmanuel De Neve, Christian Krekel, Daisy Fancourt, Nancy Hey and Gus O'Donnell. 2020. "When to release the lockdown? A wellbeing framework for analysing costs and benefits." IZA Institute of Labour Economics Working Paper DP No. 13186

Linley, P. Alex, John Maltby, Alex M. Wood, Gabrielle Osborne and Robert Hurling. 2009. "Measuring happiness: The higher order factor structure of subjective and psychological wellbeing measures." Personality and individual differences 47(8): 878-884.

Lucas, Richard E., Andrew E. Clark, Yannis Georgellis and Ed Diener. 2004. "Unemployment alters the set point for life satisfaction." Psychological science 15(1): 8-13. 
Luetke, Maya, Devon Hensel, Debby Herbenick and Molly Rosenberg. 2020. "Romantic relationship conflict due to the COVID-19 pandemic and changes in intimate and sexual behaviors in a nationally representative sample of American adults." Journal of Sex \& Marital Therapy 46(8): 747-762.

Lykken, David and Auke Tellegen. 1996. "Happiness is a stochastic phenomenon." Psychological science 7(3): 186-189.

Lyttelton, Thomas, Emma Zang and Kelly Musick. 2020. "Gender Differences in Telecommuting and Implications for Inequality at Home and Work." SocArXiv Papers DOI: $10.31235 /$ osf.io/tdf8c

Meyer, John P. and Natalie J. Allen. 1997. Commitment in the workplace: Theory, research, and application. Thousand Oaks, CA: Sage Publications.

Möhring, Katja, Elias Naumann, Maximiliane Reifenscheid, Alexander Wenz, Tobias Rettig, Ulrich Krieger, Sabine Friedel, Marina Finkel, Carina Cornesse and Annelies G. Blom. 2020. "The COVID-19 pandemic and subjective well-being: longitudinal evidence on satisfaction with work and family." European Societies: 1-17.

Moulton, Brent R. 1990. "An illustration of a pitfall in estimating the effects of aggregate variables on micro units." The review of Economics and Statistics: 334-338.

Oakman, Jodi, Natasha Kinsman, Rwth Stuckey, Melissa Graham and Victoria Weale. 2020 "A rapid review of mental and physical health effects of working at home: how do we optimise health?”. BMC Public Health 20:1825 https://doi.org/10.1186/s12889-020-09875z 
Author reference. 2020. "Making Homeworking Work: Preferences and Experiences of FullTime Workers During COVID-19"; Working paper www.publicpolicy.ie

Pierce, Matthias, Holly Hope, Tamsin Ford, Stephani Hatch, Matthew Hotopf, Ann John, Evangelos Kontopantelis et al. 2020. "Mental health before and during the COVID-19 pandemic: a longitudinal probability sample survey of the UK population." The Lancet Psychiatry 7(10): 883-892.

Rajkumar, Ravi Philip. 2020. "COVID-19 and mental health: A review of the existing literature." Asian journal of psychiatry: 102066.

Recchi, Ettore, Emanuele Ferragina, Emily Helmeid, Stefan Pauly, Mirna Safi, Nicolas Sauger, and Jen Schradie. 2020. "The "Eye of the Hurricane" Paradox: An Unexpected and Unequal Rise of Well-Being During the Covid-19 Lockdown in France." Research in Social Stratification and Mobility: 100508.

Reis, Harry T., Kennon M. Sheldon, Shelly L. Gable, Joseph Roscoe, and Richard M. Ryan. 2000. "Daily well-being: The role of autonomy, competence, and relatedness." Personality and social psychology bulletin 26(4): 419-435.

Reutrakul, Sirimon, and Kristen L. Knutson. 2015. "Consequences of circadian disruption on cardiometabolic health." Sleep medicine clinics 10(4): 455-468.

Robertson, Ivan, and Cary Cooper. 2011. Well-being: Productivity and happiness at work. Palgrave Macmillan

Ruggieri, Stefano, Sonia Ingoglia, Rubinia Celeste Bonfanti and Gianluca Lo Coco. 2020. "The role of online social comparison as a protective factor for psychological wellbeing: A longitudinal study during the COVID-19 quarantine." Personality and individual differences: 110486. DOI: 10.1016/j.paid.2020.110486. 
Ryan, Richard M. and Edward L. Deci. 2001. "On happiness and human potentials: A review of research on hedonic and eudaimonic well-being." Annual review of psychology 52(1): 141166.

Ryff, Carol D. 1989. "Happiness is everything, or is it? Explorations on the meaning of psychological well-being." Journal of personality and social psychology 57(6): 1069.

Scuffham, Paul. A., Nerina Vecchio and Harvey A. Whiteford. 2014. "Exploring the validity of HPQ-based presenteeism measures to estimate productivity losses in the health and education sectors". Medical Decision Making, 34(1), 127-137

Seligman, Martin. 2018. "PERMA and the building blocks of well-being." The Journal of Positive Psychology 13(4): 333-335.

Stanton, Jeffrey M., Evan F. Sinar, William K. Balzer, Amanda L. Julian, Paul Thoresen, Shahnaz Aziz, Gwenith G. Fisher and Patricia C. Smith. 2002. "Development of a compact measure of job satisfaction: The abridged Job Descriptive Index." Educational and Psychological Measurement 62(1): 173-191.

Wang, Cuiyan, Riyu Pan, Xiaoyang Wan, Yilin Tan, Linkang Xu, Roger S. McIntyre, Faith N. Choo et al. 2020. "A longitudinal study on the mental health of general population during the COVID-19 epidemic in China." Brain, behavior, and immunity; 87: 40-48

Warr, Peter, and S. Parker. 2010; 2016."IWP multi-affect Indicator". Sheffield, UK: Institute of Work Psychology, University of Sheffield

Wheatley, Daniel. 2020. "Workplace location and the quality of work: The case of urban-based workers in the UK." Urban Studies; DOI: 10.1177/0042098020911887 
White, S. C., 2009. "Bringing Wellbeing into Development Practice”. Working Paper. Bath, UK: University of Bath/Wellbeing in Developing Countries Research Group, (WeD Working Paper 09/50)

Winkelmann, Liliana and Rainer Winkelmann.1998. "Why are the unemployed so unhappy? Evidence from panel data." Economica 65(257): 1-15.

Zacher, Hannes, and Cort W. Rudolph. 2020. "Individual differences and changes in subjective wellbeing during the early stages of the COVID-19 pandemic." American Psychologist; July 2020; DOI: 10.1037/amp0000702 
Figure 1. COVID-19 Restrictions in the UK: Timeline (Jan 2020 - July 2020)

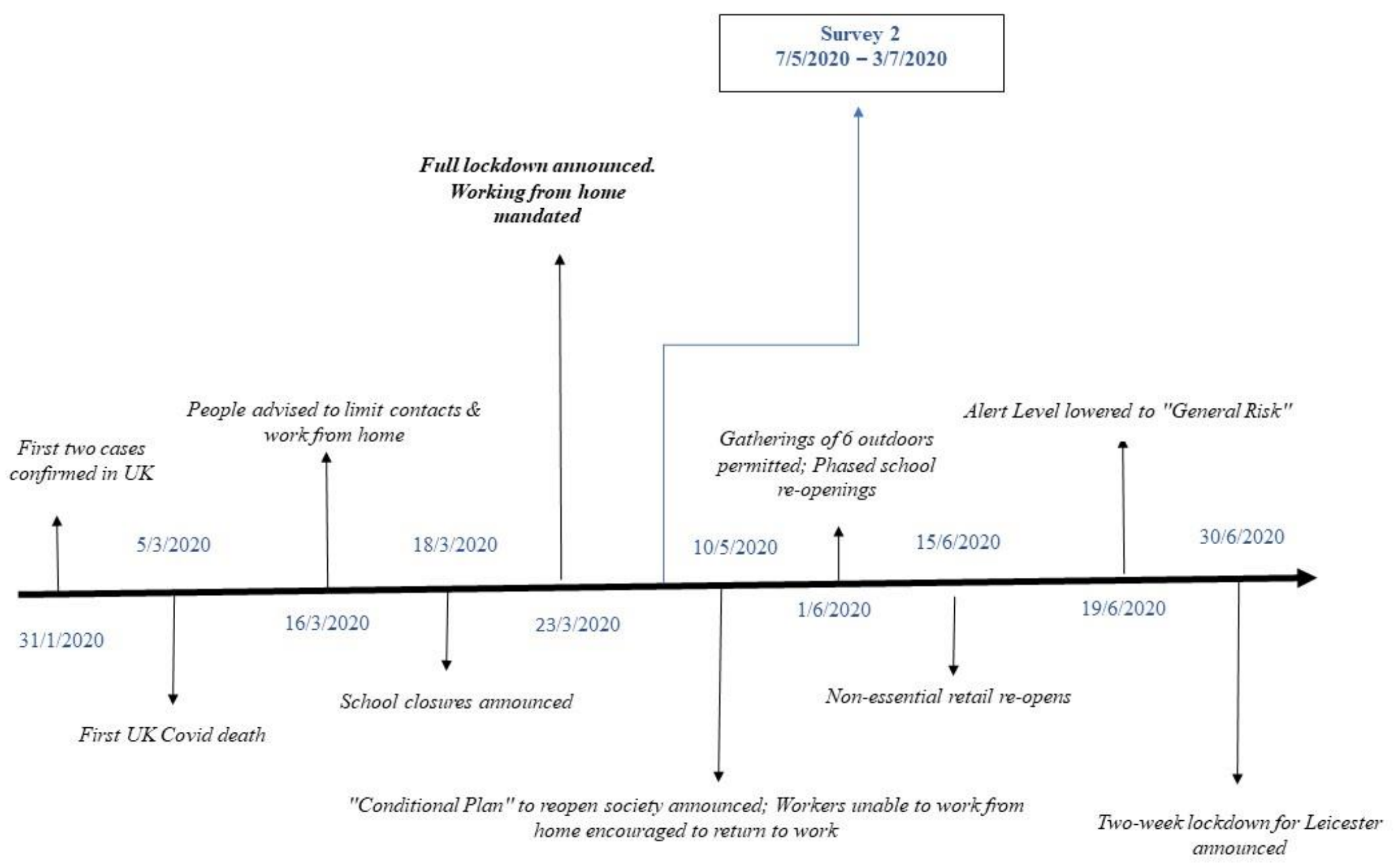




\section{SUPPLEMENTARY MATERIALS}

S1: Distribution of Responses by Month of Collection (Nov 2019 - July 2020)

S2: Comparison of Sample Characteristics with Sample used in Wheatley (2020)

S3: Full Description of Outcome Variables

S4: Pairwise Correlations between the outcome variables

S5: Descriptives - Raw Outcome Scores and t-tests by Homeworking Status

S6: Descriptives - Standardised Outcome Scores and t-tests by Homeworking Status

S7: OLS, Fixed Effects, Random Effects and Mixed Models - Standardised Main Effect (SD) by Outcome

S8: Standardised Main Effects for Female Workers by Homeworking Status

S9: Standardised Main Effects for Male Workers by Homeworking Status

S10: Global Positive Affect (IWP) -t-tests: emotions by Homeworking Status

S11: Global Negative Affect (IWP) -t-tests: emotions by Homeworking Status

S12: Experiential Positive Affect (DRM) - t-tests: emotions by Homeworking Status

S13: Experiential Negative Affect (DRM) - t-tests: emotions by Homeworking Status

S14: Ordered Logit FE model - Standardised Main Effect (SD) by Outcome Variable

S15: Permissions for use of scale 
S1. Distribution of Responses by Month of Collection (Nov 2019 - July 2020)

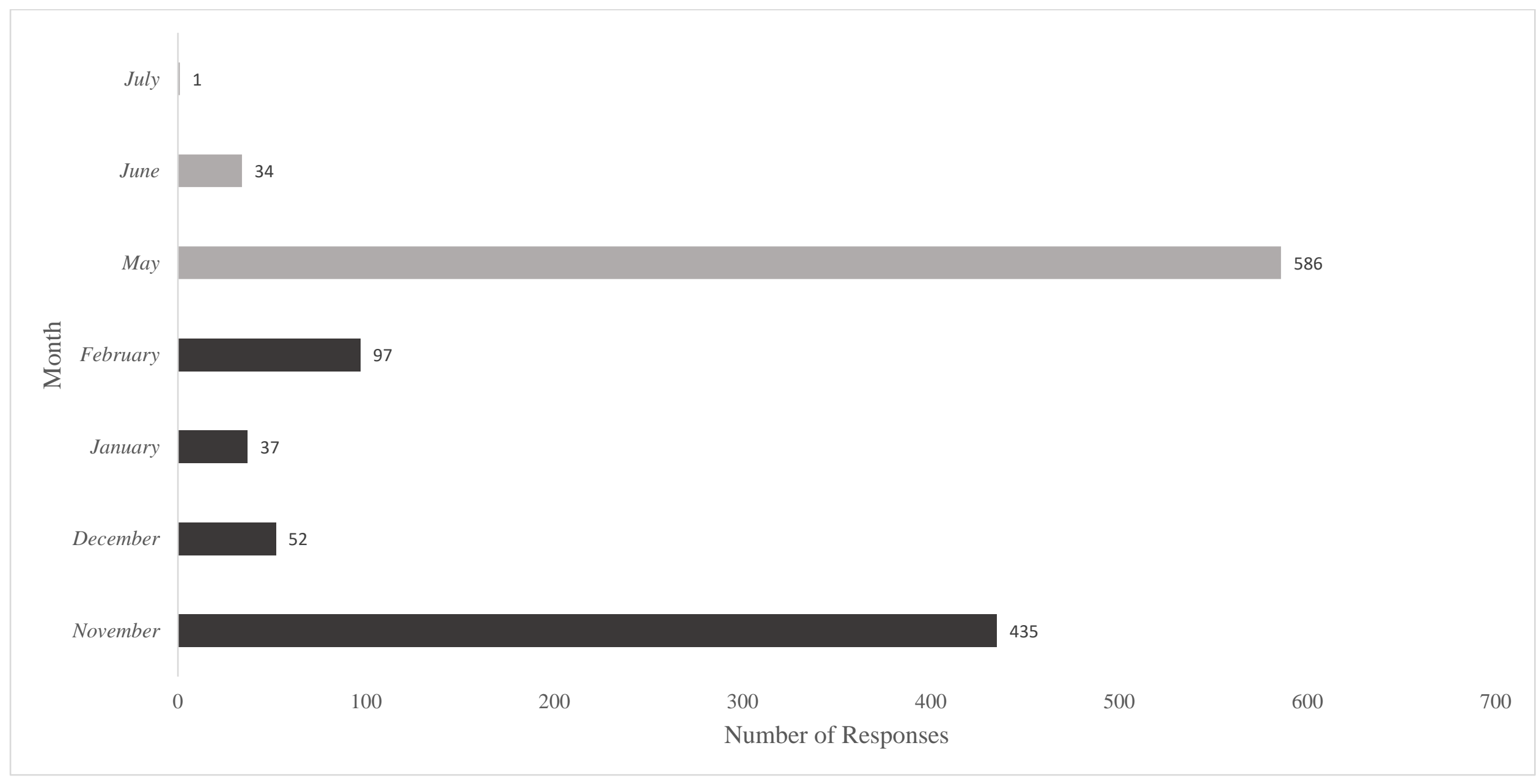


S2: Comparison of Sample Characteristics with Wheatley $(2020)^{27}$

\begin{tabular}{|c|c|c|}
\hline \multirow{2}{*}{\multicolumn{3}{|c|}{ WHEATLEY (2020) }} \\
\hline & & \\
\hline Women & $55 \%$ & $64 \%$ \\
\hline Men & $45 \%$ & $36 \%$ \\
\hline \multicolumn{3}{|l|}{ Age } \\
\hline $16-24$ & $13 \%$ & $4 \%$ \\
\hline $25-29$ & $11 \%$ & $17 \%$ \\
\hline $30-39$ & $24 \%$ & $38 \%$ \\
\hline $40-49$ & $26 \%$ & $25 \%$ \\
\hline $50-59$ & $19 \%$ & $13 \%$ \\
\hline $60-69$ & $6 \%$ & $2 \%$ \\
\hline 70 or over & $1 \%$ & $0 \%$ \\
\hline \multicolumn{3}{|l|}{ Education } \\
\hline No qualifications & $6 \%$ & $0 \%$ \\
\hline GCSE or above & $26 \%$ & $17 \%$ \\
\hline A Levels or equivalent & $37 \%$ & $21 \%$ \\
\hline Degree or above & $33 \%$ & $62 \%$ \\
\hline \multicolumn{3}{|l|}{ Country of Residence } \\
\hline England & $82 \%$ & $83 \%$ \\
\hline Wales & $6 \%$ & $3 \%$ \\
\hline Scotland & $8 \%$ & $9 \%$ \\
\hline NI & $4 \%$ & $5 \%$ \\
\hline Long term condition / disability ${ }^{28}$ & $23 \%$ & $23 \%$ \\
\hline \multicolumn{3}{|l|}{ Relationship status } \\
\hline Single / Divorced / Widowed & $49 \%$ & $26 \%$ \\
\hline In a relationship & $51 \%{ }^{29}$ & $\mathbf{7 4 \%}$ \\
\hline Annual Household income & $£ 26,600$ & $£ 24,000-£ 36,000$ \\
\hline Permanent Contract & $93 \%$ & $96 \%$ \\
\hline Overall Life Satisfaction & 5.2 & 6.5 \\
\hline Job Satisfaction & 5.3 & 6.0 \\
\hline
\end{tabular}

${ }^{27}$ Wheatley (2020) source: Understanding Society Waves 2, 4, 6 and 8. Data for Workers only. Excludes self-employed. ${ }^{2}$ Assumed to refer to a chronic physical disability.

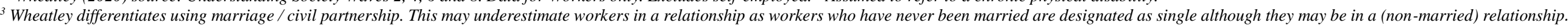




\section{S3: Full Description of Outcome Variables}

\section{VARIABLE}

\section{Overall Life Satisfaction}

Home Life Satisfaction

Overall Job Satisfaction

Self-Rated Mental Health

Work-related Stress

Sources of work stress

Multi-dimensional Job Satisfaction

Global Affect (Feelings experienced at work)

\section{QUESTION IN ABBREVIATED FORM}

Respondents are asked to rate their overall life satisfaction

Respondents are asked to rate their overall life satisfaction

Respondents are asked to rate their overall life satisfaction

Respondents are asked to rate their overall mental health status

Respondents are asked to rate the stress levels associated with their job

Respondents are asked to indicate what aspects of work are causing them the most stress

Job Descriptive Index (JDI) - Stanton, Sinar, Balzer, Julian, Thoresen, Aziz, Fisher and Smith (2002)

Respondents are asked the extent to which 6-8 adjectives relating to each of the following dimensions of job satisfaction: satisfaction with the job in general; pay; supervision; promotion opportunities; people encountered at work; the work itself; accurately describes it e.g. "Annoying”

IWP Multi-Affect Indicator (Parker \& Warr, 2010; 2016)

Respondents are asked to indicate the extent to which they experienced 16 different emotions at work during the previous month

\section{ANSWER SCALE}

$0=$ "Completely Dissatisfied"; $10=$ "Completely Satisfied"

$0=$ "Completely Dissatisfied"; $10=$ "Completely Satisfied"

$0=$ "Completely Dissatisfied"; $10=$ "Completely Satisfied"

$1=$ "Very Bad"

$5=$ "Very Good"

$=$ "Not at all stressful"

$5=$ "Extremely stressful"

15 response options e.g. "clients" and "other"

3 options for each question:

'Yes' if the word is an accurate descriptor; 'No' if the word is not an accurate descriptor and ? if the respondent is unsure

7-point Likert scale:

$1=$ "Never $(0 \%$ of the time",

$4=$ "About half of the time" (41\% to $60 \%)$

7 = "Always" ( $100 \%$ of the time")

(Recoded to 0-6 scale in our study for ease of comparison with DRM) 
Experiential Affect (Feelings experienced over 3 episodes the previous day)

Engagement / Exhaustion

Relatedness / Competence / Autonomy

Organisational Commitment (Affective Commitment)

Self-Rated Performance
Day Reconstruction Method (DRM) - Kahneman, Krueger, Schkade, Schwarz and Stone (2004)

Respondents are asked to indicate the extent to which they experienced 16 emotions during three episodes the previous day

16-item Oldenburg-Burnout Inventory (OLBI) - Demerouti \& Bakker (2008)

Respondents are asked to agree / disagree with 16 statements e.g.

"There are days when I feel tired before I arrive at work"

21-item Basic Psychological Needs Satisfaction at Work Scale Deci, Ryan, Gagné, Leone, Usunov, \& Kornazheva, 2001; 1 = "Not at all true"

Ilardi, Leone, Kasser, \& Ryan, 1993; Kasser, Davey, \& Ryan, 7 = "Very much true" 1992)

Respondents are asked to indicate the extent to which 21 statements applied to them at work over the previous month. E.g. "When I am at work..... I feel pressured at work".

6-item Affective Commitment Scale - Meyer \& Allen (1997)

Respondents are asked to agree / disagree with six statements e.g.

"I do not feel like 'part of the family' at my organization"

WHO HPQ scale - Kessler, Barber, Beck, Berglund, Cleary, $0=$ Worst Performance McKenas, Pronk, Simon, Stang, Ustun and Wang (2003)

Respondents are asked to rate their job performance over the past

month relative to the performance of a top worker
$0=$ "Not at all"

$6=$ "Very much"

$1=$ "Strongly Agree"

4 = "Strongly Disagree"
$1=$ "Strongly Agree"

$5=$ "Strongly Disagree"

$10=$ Top Performance 
S4: Pairwise Correlations between the outcome variables

\begin{tabular}{|c|c|c|c|c|c|c|c|c|c|c|c|c|c|c|c|}
\hline Variables & LS & JS & DRM PA & DRM NA & IWP PA & IWP NA & Stress & Disengage & Exhaust & Rel & Comp & Auton & $\mathrm{AC}$ & Perform & HLS \\
\hline (1) Life Satisfaction & 1.000 & & & & & & & & & & & & & & \\
\hline (2) Job Satisfaction & $0.567 *$ & 1.000 & & & & & & & & & & & & & \\
\hline (3) DRM Positive Affect & $0.384 *$ & $0.426 *$ & 1.000 & & & & & & & & & & & & \\
\hline (4) DRM Negative Affect & $-0.126^{*}$ & $-0.199 *$ & $-0.219^{*}$ & 1.000 & & & & & & & & & & & \\
\hline (5) IWP Positive Affect & $0.430 *$ & $0.580^{*}$ & $0.565^{*}$ & $-0.242 *$ & 1.000 & & & & & & & & & & \\
\hline (6) IWP Negative Affect & $-0.405 *$ & $-0.511 *$ & $-0.414 *$ & $0.304 *$ & $-0.521 *$ & 1.000 & & & & & & & & & \\
\hline (7) Stress & $-0.181 *$ & $-0.247 *$ & $-0.299^{*}$ & $0.185^{*}$ & $-0.365 *$ & $0.402 *$ & 1.000 & & & & & & & & \\
\hline (8) Disengagement & $-0.349 *$ & $-0.664 *$ & $-0.414 *$ & $0.189^{*}$ & $-0.576^{*}$ & $0.492 *$ & $0.147 *$ & 1.000 & & & & & & & \\
\hline (9) Exhaustion & $-0.385 *$ & $-0.568 *$ & $-0.474 *$ & $0.252 *$ & $-0.623^{*}$ & $0.634 *$ & $0.510^{*}$ & $0.625^{*}$ & 1.000 & & & & & & \\
\hline (10) Relatedness & $0.274 *$ & $0.384 *$ & $0.309 *$ & $-0.087 *$ & $0.336^{*}$ & $-0.335^{*}$ & $-0.116^{*}$ & $-0.414 *$ & $-0.324 *$ & 1.000 & & & & & \\
\hline (11) Competence & $0.336 *$ & $0.531 *$ & $0.384 *$ & $-0.147 *$ & $0.499 *$ & $-0.494 *$ & $-0.141^{*}$ & $-0.611 *$ & $-0.487 *$ & $0.528 *$ & 1.000 & & & & \\
\hline (12) Autonomy & $0.364 *$ & $0.532^{*}$ & $0.415^{*}$ & $-0.206^{*}$ & $0.516^{*}$ & $-0.523^{*}$ & $-0.332^{*}$ & $-0.569^{*}$ & $-0.587^{*}$ & $0.509^{*}$ & $0.632^{*}$ & 1.000 & & & \\
\hline (13) Affective Commitment & $0.287 *$ & $0.562 *$ & $0.336 *$ & $-0.093 *$ & $0.411 *$ & $-0.336 *$ & -0.051 & $-0.644 *$ & $-0.401 *$ & $0.481 *$ & $0.535^{*}$ & $0.541 *$ & 1.000 & & \\
\hline (14) Performance & $0.273^{*}$ & $0.309 *$ & $0.229 *$ & $-0.057 *$ & $0.288^{*}$ & $-0.293 *$ & $-0.115^{*}$ & $-0.243 *$ & $-0.249 *$ & $0.189^{*}$ & $0.364 *$ & $0.232 *$ & $0.178^{*}$ & 1.000 & \\
\hline (15) Homelife Satisfaction & $0.730 *$ & $0.359 *$ & $0.350^{*}$ & $-0.087 *$ & $0.313^{*}$ & $-0.298 *$ & $-0.135 *$ & $-0.201 *$ & $-0.262 *$ & $0.192 *$ & $0.232 *$ & $0.249 *$ & $0.164 *$ & $0.232 *$ & 1.000 \\
\hline
\end{tabular}


S5. Raw Outcome Scores by Homeworking Status

\begin{tabular}{|c|c|c|c|c|c|c|}
\hline & Obs & Mean Wave 1 & Mean Wave 2 & Difference & Std. Err & p-value \\
\hline \multicolumn{7}{|l|}{ Whole Sample } \\
\hline Life Satisfaction (0-10) & 620 & 6.628 & 6.562 & -.066 & .067 & .323 \\
\hline Homelife Satisfaction (0-10) & 617 & 7.173 & 6.952 & -.222 & .073 & $.003^{* * *}$ \\
\hline Job satisfaction $(0-10)$ & 617 & 5.979 & 6.109 & .130 & .081 & .107 \\
\hline Episodic Pos Affect (0-6) & 596 & 2.907 & 2.971 & .064 & .042 & .123 \\
\hline Episodic Neg Affect (0-6) & 596 & 2.111 & 2.001 & -.111 & .039 & $.005^{* * *}$ \\
\hline Global Pos Affect (0-6) & 618 & 2.552 & 2.530 & -.023 & .039 & .563 \\
\hline Global Neg Affect (0-6) & 618 & 1.558 & 1.504 & -.054 & .036 & .141 \\
\hline Work Stress (1-5) & 611 & 3.080 & 3.066 & -.015 & .033 & .655 \\
\hline Disengagement (1-4) & 618 & 2.470 & 2.389 & -.080 & .018 & $<.001^{* * *}$ \\
\hline Exhaustion (1-4) & 618 & 2.535 & 2.425 & -.111 & .017 & $<.001^{* * *}$ \\
\hline Relatedness (1-7) & 619 & 4.953 & 5.014 & .061 & .017 & $.001^{* * *}$ \\
\hline Competence (1-7) & 619 & 4.973 & 5.046 & .073 & .020 & $.001^{* * *}$ \\
\hline Autonomy (1-7) & 619 & 4.421 & 4.538 & .116 & .022 & $<.001^{* * *}$ \\
\hline Org. Commitment (1-5) & 616 & 2.982 & 3.170 & .188 & .032 & $<.001^{* * *}$ \\
\hline Performance $(0-10)$ & 615 & 7.612 & 7.107 & -.504 & .072 & $<.001^{* * *}$ \\
\hline Mental Health (1-5) & 613 & 3.614 & 3.639 & .026 & .031 & .400 \\
\hline \multicolumn{7}{|l|}{ Non-Homeworkers } \\
\hline Life Satisfaction (0-10) & 140 & 6.457 & 6.357 & -.100 & .158 & .527 \\
\hline Homelife Satisfaction (0-10) & 140 & 6.986 & 6.793 & -.193 & .177 & .279 \\
\hline Job satisfaction $(0-10)$ & 139 & 5.841 & 5.813 & -.029 & .206 & .889 \\
\hline Episodic Pos Affect (0-6) & 133 & 2.813 & 2.877 & .065 & .089 & .470 \\
\hline Episodic Neg Affect (0-6) & 133 & 2.037 & 2.123 & .086 & .077 & .268 \\
\hline Global Pos Affect (0-6) & 140 & 2.533 & 2.522 & -.011 & .090 & .904 \\
\hline Global Neg Affect (0-6) & 140 & 1.552 & 1.482 & -.071 & .075 & .344 \\
\hline
\end{tabular}


Work Stress (1-5)

Disengagement (1-4)

Exhaustion (1-4)

Relatedness (1-7)

Competence (1-7)

Autonomy (1-7)

Org. Commitment (1-5)

Performance (0-10)

Mental Health (1-5)

\section{Homeworkers}

Life Satisfaction (0-10)

Homelife Satisfaction (0-10)

Job satisfaction (0-10)

Episodic Pos Affect (0-6)

Episodic Neg Affect (0-6)

Global Pos Affect (0-6)

Global Neg Affect (0-6)

Work Stress (1-5)

Disengagement (1-4)

Exhaustion (1-4)

Relatedness (1-7)

Competence (1-7)

Autonomy (1-7)

Org. Commitment (1-5)

Performance (0-10)

Mental Health (1-5)

$\begin{array}{ll}3.124 & 3.081 \\ 2.571 & 2.486 \\ 2.667 & 2.541 \\ 4.912 & 4.969 \\ 5.026 & 5.069 \\ 4.280 & 4.378 \\ 2.900 & 3.042 \\ 7.633 & 7.511 \\ 3.489 & 3.621\end{array}$

$-.044$

$-.085$

$-.126$

.057

.043

.098

.142

$-.122$

.131

6.614
6.998
6.192
2.992
1.973
2.530
1.513
3.070
2.360
2.393
5.023
5.037
4.588
3.211
6.992
3.643

$-.063$

$-.228$

.173

.062

$-.161$

$-.023$

$-.051$

$-.002$

$-.080$

$-.106$

.062

.082

.128

.203

$-.613$

.000
.077

.039

.035

.037

.041

.051

.064

.149

.066

\section{.073}

.080

.085

.046

.044

.044

.042

.036

.020

.018

.018

.023

.025

.036

.082

.035
.573

$.030^{* * *}$

$.001^{* * * *}$

.132

.302

$.057^{*}$

$.028^{* * *}$

.414

$.049^{* * *}$

.392

$.005^{* * *}$

$.044^{* *}$

.184

$.001^{* * * *}$

.598

.227

.954

$<.001^{* * *}$

$<.001^{* * *}$

$.001^{* * *}$

$.001^{* * * *}$

$<.001^{* * * *}$

$<.001^{* * * *}$

$<.001^{* * * *}$

1.00 
S6. Descriptives - Standardised Outcome Scores by Homeworking Status

\begin{tabular}{|c|c|c|c|c|c|c|}
\hline & $N$ & Mean Wave 1 & Mean Wave 2 & Difference & Std. Err & $p$-value \\
\hline \multicolumn{7}{|l|}{ Whole Sample } \\
\hline Life satisfaction & 620 & .018 & -.018 & -.036 & .036 & .323 \\
\hline Homelife satisfaction & 617 & .052 & -.056 & $-.108^{* * *}$ & .036 & .003 \\
\hline Job satisfaction & 617 & -.029 & .030 & .059 & .037 & .107 \\
\hline Episodic Pos Affect (DRM) & 596 & -.028 & .038 & .066 & .043 & .123 \\
\hline Episodic Neg Affect (DRM) & 596 & .072 & -.079 & $-.150^{* * * *}$ & .053 & .005 \\
\hline Global Pos Affect (IWP) & 618 & .011 & -.009 & -.020 & .035 & .563 \\
\hline Global Neg Affect (IWP) & 618 & .025 & -.021 & -.046 & .032 & .141 \\
\hline Work Stress & 611 & .006 & -.008 & -.014 & .033 & .655 \\
\hline Disengagement & 618 & .068 & -.073 & $-.141^{* * * *}$ & .031 & $<.001$ \\
\hline Exhaustion & 618 & .099 & -.100 & $-.199^{* * * *}$ & .030 & $<.001$ \\
\hline Relatedness & 619 & -.030 & .028 & $.058^{* * *}$ & .015 & .001 \\
\hline Competence & 619 & -.036 & .036 & $.073^{* * *}$ & .020 & .001 \\
\hline Autonomy & 619 & -.057 & .053 & $.110^{* * *}$ & .022 & $<.001$ \\
\hline Affective Commitment & 616 & -.092 & .093 & $.185^{* * *}$ & .031 & $<.001$ \\
\hline Performance & 615 & .154 & -.157 & $-.311^{* * * *}$ & .044 & $<.001$ \\
\hline Mental Health & 613 & -.014 & .015 & .029 & .035 & .400 \\
\hline \multicolumn{7}{|l|}{ Non-Homeworkers } \\
\hline Life satisfaction & 140 & -.074 & -.129 & -.054 & .086 & .527 \\
\hline Homelife satisfaction & 140 & -.039 & -.133 & -.094 & .087 & .279 \\
\hline Job satisfaction & 139 & -.092 & -.105 & -.013 & .094 & .889 \\
\hline Episodic Pos Affect (DRM) & 133 & -.127 & -.060 & .067 & .092 & .470 \\
\hline Episodic Neg Affect (DRM) & 133 & -.030 & .088 & .117 & .105 & .268 \\
\hline Global Pos Affect (IWP) & 140 & -.006 & -.015 & -.010 & .081 & .904 \\
\hline Global Neg Affect (IWP) & 140 & .021 & -.041 & -.061 & .065 & .344 \\
\hline
\end{tabular}




\begin{tabular}{|c|c|c|c|c|c|c|}
\hline Work Stress & 137 & .049 & .007 & -.043 & .076 & .573 \\
\hline Disengagement & 139 & .247 & .097 & $-.150^{* *}$ & .069 & .030 \\
\hline Exhaustion & 139 & .335 & .109 & $-.226^{* *}$ & .064 & .001 \\
\hline Relatedness & 140 & -.069 & -.015 & .054 & .036 & .132 \\
\hline Competence & 140 & .017 & .060 & .043 & .041 & .302 \\
\hline Autonomy & 140 & -.191 & -.098 & $.093^{*}$ & .049 & .057 \\
\hline Affective Commitment & 138 & -.173 & -.033 & $.140^{* *}$ & .063 & .028 \\
\hline Performance & 139 & .168 & .092 & -.075 & .092 & .414 \\
\hline Mental Health & 137 & -.154 & -.006 & $.148^{* *}$ & .074 & .049 \\
\hline \multicolumn{7}{|l|}{ Homeworkers } \\
\hline Life satisfaction & 476 & .044 & .010 & -.034 & .040 & .392 \\
\hline Homelife satisfaction & 473 & .079 & -.033 & $-.111^{* * *}$ & .038 & .005 \\
\hline Job satisfaction & 475 & -.011 & .068 & $.079^{*}$ & .039 & .044 \\
\hline Episodic Pos Affect (DRM) & 460 & -.004 & .060 & .064 & .049 & .184 \\
\hline Episodic Neg Affect (DRM) & 460 & .103 & -.117 & $-.219^{* * *}$ & .060 & .001 \\
\hline Global Pos Affect (IWP) & 475 & .011 & -.009 & -.021 & .039 & .598 \\
\hline Global Neg Affect (IWP) & 475 & .031 & -.013 & -.044 & .036 & .227 \\
\hline Work Stress & 470 & -.002 & -.004 & -.002 & .036 & .954 \\
\hline Disengagement & 476 & .015 & -.125 & $-.140^{* * *}$ & .035 & $<.001$ \\
\hline Exhaustion & 476 & .034 & -.157 & $-.191^{* * *}$ & .034 & $<.001$ \\
\hline Relatedness & 475 & -.022 & .037 & $.059^{* * *}$ & .018 & .001 \\
\hline Competence & 475 & -.054 & .029 & $.082^{* * *}$ & .023 & .001 \\
\hline Autonomy & 475 & -.021 & .100 & $.121^{* * *}$ & .024 & $<.001$ \\
\hline Affective Commitment & 475 & -.066 & .134 & $.200^{* * *}$ & .036 & $<.001$ \\
\hline Performance & 473 & .15 & -.228 & $-.378^{* * *}$ & .051 & $<.001$ \\
\hline Mental Health & 473 & .019 & .019 & .000 & .040 & 1.00 \\
\hline
\end{tabular}


S7. Standardised Main Effects (SD) by Outcome - comparison of OLS, Fixed Effects, Random Effects and Mixed Models

\begin{tabular}{|c|c|c|c|c|}
\hline Variable & Coefficient (SD change) OLS & Coefficient (SD change) FE & Coefficient (SD change) RE & Coefficient (SD change) Mixed \\
\hline \multirow[t]{2}{*}{ Life Satisfaction } & -.036 & -.036 & -.036 & -.036 \\
\hline & $(.057)$ & $(.036)$ & $(.036)$ & $(.036)$ \\
\hline Homelife Satisfaction & $-.109 *$ & $-.108 * * *$ & $-.109 * * *$ & $-.109 * * *$ \\
\hline \multirow[t]{2}{*}{ Job Satisfaction } & .063 & .059 & $.061 *$ & $.061 *$ \\
\hline & $(.057)$ & $(.037)$ & $(.037)$ & $(.037)$ \\
\hline \multirow[t]{2}{*}{ Global Positive Affect } & -.019 & -.020 & -.020 & -.020 \\
\hline & $(.057)$ & $(.035)$ & $(.035)$ & $(.035)$ \\
\hline \multirow{2}{*}{ Global Negative Affect } & -.045 & -.046 & -.046 & -.046 \\
\hline & $(.057)$ & $(.031)$ & $(.031)$ & $(.031)$ \\
\hline \multirow[t]{2}{*}{ Experiential positive affect } & .073 & .066 & .070 & .070 \\
\hline & $(.057)$ & $(.043)$ & $(.043)$ & $(.043)$ \\
\hline \multirow[t]{2}{*}{ Experiential negative affect } & $-.164 * * *$ & $-.150 * * *$ & $-.162 * * *$ & $-.162 * * *$ \\
\hline & $(.053)$ & $(.053)$ & $(.053)$ & $(.053)$ \\
\hline \multirow{2}{*}{ Work Stress } & -.017 & -.014 & -.015 & -.015 \\
\hline & $(.057)$ & $(.032)$ & $(.032)$ & $(.032)$ \\
\hline \multirow[t]{2}{*}{ Exhaustion } & $-.200 * * *$ & $-.199 * * *$ & $-.199 * * *$ & $-.199 * * *$ \\
\hline & $(.056)$ & $(.029)$ & $(.029)$ & $(.029)$ \\
\hline \multirow[t]{2}{*}{ Relatedness } & .060 & $.058 * * *$ & $.058 * * *$ & $.058 * * *$ \\
\hline & $(.056)$ & $(.016)$ & $(.016)$ & $(.016)$ \\
\hline \multirow[t]{2}{*}{ Competence } & .079 & $.073 * * *$ & $.073 * * *$ & $.073 * * *$ \\
\hline & $(.056)$ & $(.020)$ & $(.020)$ & $(.020)$ \\
\hline \multirow[t]{2}{*}{ Autonomy } & $.114 * *$ & $.110 * * *$ & $.110 * * *$ & $.110 * * *$ \\
\hline & $(.056)$ & $(.021)$ & $(.021)$ & $(.021)$ \\
\hline \multirow[t]{2}{*}{ Affective Commitment } & $.186^{* * *}$ & $.185^{* * *}$ & $.185^{* * *}$ & $.185^{* * *}$ \\
\hline & $(.056)$ & $(.031)$ & $(.031)$ & $(.031)$ \\
\hline \multirow[t]{2}{*}{ Mental Health } & .035 & .029 & .032 & .032 \\
\hline & $(.056)$ & $(.034)$ & $(.034)$ & $(.034)$ \\
\hline \multirow[t]{2}{*}{ Performance } & $-.306^{* * *}$ & $-.311 * * *$ & $-.308 * * *$ & $-.308 * * *$ \\
\hline & $(.056)$ & $(.045)$ & $(.044)$ & $(.044)$ \\
\hline
\end{tabular}


S8. Standardised Main Effects for Female Workers by Homeworking Status

\begin{tabular}{|c|c|c|c|c|}
\hline \multirow[t]{2}{*}{ Variable } & NHW & Obs & \multirow{2}{*}{$\begin{array}{c}\text { HW } \\
\text { Coefficient (SD) }\end{array}$} & \multirow[t]{2}{*}{ Obs } \\
\hline & Coefficient (SD) & & & \\
\hline Life Satisfaction & $-.018(.126)$ & 172 & $-.023(.051)$ & 611 \\
\hline Homelife Satisfaction & $.022(.120)$ & 172 & $-.139^{* * * *}(.049)$ & 609 \\
\hline Job Satisfaction & $.080(.134)$ & 171 & $.111^{* *}(.050)$ & 610 \\
\hline Global Positive Affect (IWP) & $.190 *(.103)$ & 172 & $-.013(.051)$ & 610 \\
\hline Global Negative Affect (IWP) & $-.071(.093)$ & 172 & $-.109^{* *}(.047)$ & 610 \\
\hline Episodic Positive Affect (DRM) & $.100(.121)$ & 165 & $.040(.064)$ & 597 \\
\hline Episodic Negative Affect (DRM) & $.232^{*}(.126)$ & 165 & $-.228^{* * * *}(.080)$ & 597 \\
\hline Work Stress & $-.046(.094)$ & 170 & $-.026(.046)$ & 606 \\
\hline Disengagement & $-.227^{* *}(.096)$ & 171 & $-.195^{* * * *}(.046)$ & 611 \\
\hline Exhaustion & $-.283^{* * * *}(.091)$ & 171 & $-.207^{* * * *}(.042)$ & 611 \\
\hline Relatedness & $.094^{* *}(.045)$ & 172 & $.064^{* * * *}(.023)$ & 610 \\
\hline Competence & $.089(.054)$ & 172 & $.095^{* * *}(.030)$ & 610 \\
\hline Autonomy & $.162^{* *}(.064)$ & 172 & $.165^{* * *}(.030)$ & 610 \\
\hline Affective Commitment & $.199^{* *}(.085)$ & 170 & $.219^{* * *}(.046)$ & 611 \\
\hline Mental Health & $.013(.095)$ & 171 & $-.033(.050)$ & 608 \\
\hline Performance & $-.050(.115)$ & 171 & $-.374^{* * * *}(.062)$ & 608 \\
\hline
\end{tabular}

$* * * p<0.01, * * p<0.05, * p<0.1$. Robust Clustered Standard Errors. Standardised variables used throughout. Non-Adjusted p-value 
S9. Standardised Main Effects for Male Workers by Homeworking Status

\begin{tabular}{|c|c|c|c|c|}
\hline \multirow[t]{2}{*}{ Variable } & \multirow[b]{2}{*}{ Coefficient (SD) } & Obs & \multirow{2}{*}{$\begin{array}{c}\text { HW } \\
\text { Coefficient (SD) }\end{array}$} & \multirow[t]{2}{*}{ Obs } \\
\hline & & & & \\
\hline Life Satisfaction & $-.122(.095)$ & 106 & $-.051(.063)$ & 334 \\
\hline Homelife Satisfaction & $-.284^{* *}(.115)$ & 106 & $-.061(.062)$ & 333 \\
\hline Job Satisfaction & $-.155(.120)$ & 106 & $.013(.061)$ & 334 \\
\hline Global Positive Affect & $-.307^{* *}(.119)$ & 106 & $-.035(.059)$ & 334 \\
\hline Global Negative Affect & $-.040(.079)$ & 106 & $.070(.053)$ & 334 \\
\hline Episodic Positive Affect & $.024(.147)$ & 105 & $.108(.073)$ & 331 \\
\hline Episodic Negative Affect & $-.055(.185)$ & 105 & $-.197^{* * *}(.092)$ & 331 \\
\hline Work Stress & $-.037(.132)$ & 105 & $.029(.055)$ & 333 \\
\hline Disengagement & $-.020(.092)$ & 106 & $-.023(.052)$ & 334 \\
\hline Exhaustion & $-.133^{*}(.077)$ & 106 & $-.161^{* * * *}(.053)$ & 334 \\
\hline Relatedness & $.000(.058)$ & 106 & $.046 *(.026)$ & 334 \\
\hline Competence & $-.028(.063)$ & 106 & $.052(.034)$ & 334 \\
\hline Autonomy & $-.012(.072)$ & 106 & $.035(.035)$ & 334 \\
\hline Affective Commitment & $.055(.093)$ & 106 & $.138^{* * * *}(.053)$ & 333 \\
\hline Mental Health & $.353^{* * *}(.116)$ & 104 & $.053(.064)$ & 334 \\
\hline Performance & $-.116(.158)$ & 106 & $-.391^{* * * *}(.086)$ & 334 \\
\hline
\end{tabular}

*** $p<0.01, * * p<0.05, * p<0.1$. Non-adjusted $p$-values. Robust Clustered Standard Errors. Standardised variables used throughout 
S10. Global Positive Affect (IWP) - t-tests: emotions by Homeworking Status

\begin{tabular}{|c|c|c|c|c|c|c|}
\hline & Obs & Mean Wave 1 & Mean Wave 2 & Difference & Std. Error & $p$-value \\
\hline \multicolumn{7}{|l|}{ Whole Sample } \\
\hline Calm & 617 & 3.324 & 3.342 & .018 & .054 & .744 \\
\hline At Ease & 615 & 2.699 & 2.785 & .086 & .065 & .187 \\
\hline Relaxed & 617 & 2.692 & 2.83 & $.138^{* *}$ & .059 & .019 \\
\hline Laid Back & 616 & 2.372 & 2.484 & $.112^{*}$ & .063 & .076 \\
\hline Enthusiastic & 618 & 3.055 & 2.813 & $-.243^{* * *}$ & .052 & $<.001$ \\
\hline Joyful & 618 & 2.24 & 2.147 & $-.092^{*}$ & .054 & .092 \\
\hline Excited & 610 & 1.836 & 1.715 & $-.121^{* *}$ & .054 & .025 \\
\hline Inspired & 616 & 2.18 & 2.087 & -.093 & .057 & .102 \\
\hline \multicolumn{7}{|c|}{ Non-Homeworkers } \\
\hline Calm & 140 & 3.293 & 3.379 & .086 & .116 & .462 \\
\hline At Ease & 139 & 2.727 & 2.727 & .000 & .143 & 1.00 \\
\hline Relaxed & 140 & 2.671 & 2.679 & .007 & .122 & .954 \\
\hline Laid Back & 139 & 2.389 & 2.295 & -.094 & .144 & .515 \\
\hline Enthusiastic & 140 & 3.035 & 2.914 & -.121 & .112 & .281 \\
\hline Joyful & 140 & 2.315 & 2.393 & .079 & .126 & .532 \\
\hline Excited & 137 & 1.737 & 1.679 & -.058 & .122 & .635 \\
\hline Inspired & 139 & 2.021 & 2.007 & -.014 & .128 & .901 \\
\hline \multicolumn{7}{|l|}{ Homeworkers } \\
\hline Calm & 474 & 3.327 & 3.333 & .006 & .062 & .918 \\
\hline At Ease & 473 & 2.689 & 2.799 & .110 & .073 & .136 \\
\hline Relaxed & 474 & 2.694 & 2.873 & $.179^{* * *}$ & .068 & .008 \\
\hline Laid Back & 474 & 2.359 & 2.538 & $.179^{* *}$ & .070 & .011 \\
\hline Enthusiastic & 475 & 3.057 & 2.781 & $-.276^{* * *}$ & .060 & $<.001$ \\
\hline Joyful & 475 & 2.211 & 2.071 & $-.139^{* *}$ & .060 & .022 \\
\hline Excited & 470 & 1.857 & 1.722 & $-.136^{* *}$ & .060 & .024 \\
\hline Inspired & 474 & 2.226 & 2.110 & $-.116^{*}$ & .063 & .066 \\
\hline
\end{tabular}


S11. Global Negative Affect (IWP)- t-tests: emotions by Homeworking Status

\begin{tabular}{|c|c|c|c|c|c|c|}
\hline & Obs & Mean Wave 1 & Mean Wave 2 & Difference & Std. Error & p-value \\
\hline \multicolumn{7}{|c|}{ Whole Sample } \\
\hline Depressed & 618 & 1.379 & 1.322 & -.057 & .051 & .264 \\
\hline Despondent & 601 & 1.393 & 1.278 & -.115 & .054 & .034 \\
\hline Dejected & 612 & 1.496 & 1.236 & $-.261^{* * *}$ & .057 & $<.001$ \\
\hline Hopeless & 614 & 1.069 & .945 & $-.124^{* *}$ & .052 & .019 \\
\hline Anxious & 617 & 1.806 & 1.898 & $.092^{*}$ & .054 & .089 \\
\hline Tense & 615 & 1.933 & 1.787 & $-.146^{* * *}$ & .056 & .009 \\
\hline Worried & 615 & 1.830 & 1.948 & $.119^{* *}$ & .058 & .039 \\
\hline Nervous & 616 & 1.540 & 1.611 & .070 & .051 & .170 \\
\hline \multicolumn{7}{|c|}{ Non-Homeworkers } \\
\hline Depressed & 140 & 1.421 & 1.322 & -.100 & .098 & .306 \\
\hline Despondent & 131 & 1.351 & 1.199 & -.153 & .106 & .154 \\
\hline Dejected & 137 & 1.379 & 1.226 & -.153 & .122 & .211 \\
\hline Hopeless & 138 & 1.058 & .898 & -.159 & .106 & .135 \\
\hline Anxious & 140 & 1.793 & 1.900 & .107 & .106 & .315 \\
\hline Tense & 139 & 2.029 & 1.842 & -.187 & .128 & .146 \\
\hline Worried & 138 & 1.826 & 1.971 & .145 & .127 & .255 \\
\hline Nervous & 140 & 1.550 & 1.514 & -.036 & .102 & .727 \\
\hline \multicolumn{7}{|l|}{ Homeworkers } \\
\hline Depressed & 475 & 1.373 & 1.324 & -.048 & .059 & .414 \\
\hline Despondent & 467 & 1.407 & 1.302 & $-.105^{*}$ & .063 & .096 \\
\hline Dejected & 472 & 1.536 & 1.24 & $-.297^{* * *}$ & .065 & $<.001$ \\
\hline Hopeless & 473 & 1.074 & .956 & $-.118^{*}$ & .06 & .052 \\
\hline Anxious & 474 & 1.817 & 1.901 & .084 & .064 & .183 \\
\hline Tense & 473 & 1.911 & 1.780 & $-.131^{* *}$ & .062 & .035 \\
\hline Worried & 474 & 1.834 & 1.945 & $.112^{*}$ & .065 & .085 \\
\hline Nervous & 473 & 1.546 & 1.643 & $.097^{*}$ & .059 & .099 \\
\hline
\end{tabular}


S12. Experiential Positive Affect (DRM) - t-tests: emotions by Homeworking Status

\begin{tabular}{|c|c|c|c|c|c|c|}
\hline & Obs & Pre-Lockdown & During Lockdown & Difference & St Err & $p$-value \\
\hline \multicolumn{7}{|l|}{ Whole Sample } \\
\hline Calm & 577 & 3.579 & 3.678 & $.099^{*}$ & .054 & .071 \\
\hline At Ease & 574 & 3.284 & 3.401 & $.117^{*}$ & .060 & .052 \\
\hline Relaxed & 577 & 3.265 & 3.420 & $.154^{* *}$ & .060 & .011 \\
\hline Laid Back & 571 & 3.027 & 3.170 & $.143^{* *}$ & .059 & .015 \\
\hline Enthusiastic & 577 & 3.026 & 3.011 & -.014 & .056 & .797 \\
\hline Joyful & 573 & 2.368 & 2.413 & .045 & .057 & .427 \\
\hline Excited & 567 & 2.252 & 2.226 & -.026 & .057 & .641 \\
\hline Inspired & 565 & 2.417 & 2.458 & .041 & .054 & .445 \\
\hline \multicolumn{7}{|c|}{ Non-Homeworkers } \\
\hline Calm & 128 & 3.554 & 3.521 & -.034 & .105 & .748 \\
\hline At Ease & 128 & 3.208 & 3.279 & .070 & .129 & .585 \\
\hline Relaxed & 131 & 3.292 & 3.28 & -.013 & .121 & .916 \\
\hline Laid Back & 127 & 2.895 & 3.021 & .126 & .132 & .339 \\
\hline Enthusiastic & 131 & 2.820 & 2.807 & -.013 & .128 & .921 \\
\hline Joyful & 127 & 2.362 & 2.570 & $.207^{*}$ & .121 & .090 \\
\hline Excited & 124 & 2.199 & 2.220 & .022 & .114 & .850 \\
\hline Inspired & 123 & 2.349 & 2.292 & -.057 & .117 & .628 \\
\hline \multicolumn{7}{|l|}{ Homeworkers } \\
\hline Calm & 447 & 3.587 & 3.727 & $.139^{* *}$ & .064 & .030 \\
\hline At Ease & 444 & 3.310 & 3.438 & $.128^{*}$ & .069 & .063 \\
\hline Relaxed & 444 & 3.260 & 3.462 & $.201^{* * * *}$ & .069 & .004 \\
\hline Laid Back & 442 & 3.068 & 3.216 & $.148^{* *}$ & .066 & .026 \\
\hline Enthusiastic & 445 & 3.086 & 3.074 & -.013 & .063 & .839 \\
\hline Joyful & 445 & 2.367 & 2.368 & .001 & .064 & .991 \\
\hline Excited & 441 & 2.265 & 2.226 & -.039 & .066 & .547 \\
\hline Inspired & 441 & 2.430 & 2.505 & .075 & .060 & .218 \\
\hline
\end{tabular}


S13. Standardised Experiential Negative Affect scores (DRM) - individual emotions Status

\begin{tabular}{|c|c|c|c|c|c|c|}
\hline & Obs & Mean Wave 1 & Mean Wave 2 & Difference & Std. Error & $p$-value \\
\hline \multicolumn{7}{|c|}{ Whole Sample } \\
\hline Depressed & 572 & 2.000 & 2.011 & .012 & .045 & .799 \\
\hline Despondent & 559 & 2.081 & 2.035 & -.046 & .049 & .349 \\
\hline Dejected & 565 & 2.096 & 2.017 & $-.080^{*}$ & .044 & .071 \\
\hline Hopeless & 570 & 2.003 & 1.986 & -.018 & .044 & .691 \\
\hline Anxious & 576 & 2.170 & 2.049 & $-.121^{* *}$ & .054 & .026 \\
\hline Tense & 570 & 2.240 & 2.087 & $-.154^{* * *}$ & .058 & .007 \\
\hline Worried & 571 & 2.091 & 2.005 & -.086 & .053 & .103 \\
\hline Nervous & 580 & 2.111 & 2.017 & $-.095^{*}$ & .050 & .058 \\
\hline \multicolumn{7}{|c|}{ Non-Homeworkers } \\
\hline Depressed & 127 & 2.002 & 2.095 & .092 & .101 & .364 \\
\hline Despondent & 123 & 1.965 & 2.208 & $.244^{* *}$ & .098 & .014 \\
\hline Dejected & 126 & 2.037 & 2.162 & .124 & .085 & .145 \\
\hline Hopeless & 125 & 2.022 & 2.099 & .077 & .100 & .438 \\
\hline Anxious & 129 & 2.039 & 2.124 & .085 & .108 & .434 \\
\hline Tense & 126 & 2.220 & 2.267 & .048 & .122 & .699 \\
\hline Worried & 128 & 2.050 & 2.196 & .146 & .107 & .175 \\
\hline Nervous & 130 & 1.925 & 2.128 & $.203^{*}$ & .101 & .047 \\
\hline \multicolumn{7}{|l|}{ Homeworkers } \\
\hline Depressed & 443 & 2.003 & 1.988 & -.015 & .052 & .769 \\
\hline Despondent & 434 & 2.115 & 1.986 & $-.128^{* *}$ & .056 & .022 \\
\hline Dejected & 437 & 2.115 & 1.975 & $-.140^{* * *}$ & .051 & .006 \\
\hline Hopeless & 443 & 2.001 & 1.954 & -.047 & .049 & .344 \\
\hline Anxious & 445 & 2.207 & 2.030 & $-.176^{* * *}$ & .062 & .005 \\
\hline Tense & 442 & 2.244 & 2.038 & $-.207^{* * *}$ & .065 & .002 \\
\hline Worried & 441 & 2.102 & 1.951 & $-.151^{* * *}$ & .060 & .013 \\
\hline Nervous & 448 & 2.166 & 1.985 & $-.181^{* * *}$ & .057 & .002 \\
\hline
\end{tabular}


S14: Ordered Logit FE model - Standardised Main Effect (SD) by Outcome

\begin{tabular}{|c|c|c|}
\hline Variable & Coefficient (SD change) & Log Conditional Likelihood \\
\hline Life Satisfaction & $\begin{array}{l}-.119 \\
(.120)\end{array}$ & -474.967 \\
\hline Homelife Satisfaction & $\begin{array}{c}-.341^{* * * *} \\
(.113)\end{array}$ & -550.515 \\
\hline Job Satisfaction & $\begin{array}{l}.181 \\
(.112)\end{array}$ & -610.511 \\
\hline Global Positive Affect (IWP) & $\begin{array}{l}-.068 \\
(.107)\end{array}$ & -3362.356 \\
\hline Global Negative Affect (IWP) & $\begin{array}{l}-.173 \\
(.109)\end{array}$ & -3251.211 \\
\hline Episodic Positive Affect (DRM) & $\begin{array}{l}.161 \\
(.107)\end{array}$ & -9490.099 \\
\hline Episodic Negative Affect (DRM) & $\begin{array}{c}-.296^{* * *} \\
(.109)\end{array}$ & -8515.229 \\
\hline Work Stress & $\begin{array}{l}-.055 \\
(.124)\end{array}$ & -223.761 \\
\hline Disengagement & $\begin{array}{c}-.503^{* * * *} \\
(.112)\end{array}$ & -2235.030 \\
\hline Exhaustion & $\begin{array}{c}-.754^{* * * * *} \\
(.112)\end{array}$ & -2061.411 \\
\hline Relatedness & $\begin{array}{l}.444^{* * * *} \\
(.114)\end{array}$ & -1460.603 \\
\hline Competence & $\begin{array}{l}.362^{* * * *} \\
(.109)\end{array}$ & -1319.527 \\
\hline Autonomy & $\begin{array}{l}.542^{* * * *} \\
(.112)\end{array}$ & -1998.572 \\
\hline Affective Commitment & $\begin{array}{l}.663^{* * * *} \\
(.104)\end{array}$ & -1804.448 \\
\hline Mental Health & $\begin{array}{l}.108 \\
(.129)\end{array}$ & -203.349 \\
\hline Performance & $\begin{array}{c}-.804^{* * * * *} \\
(.115) \\
\end{array}$ & -502.132 \\
\hline
\end{tabular}

Staub, and R. Winkelmann 2015. Consistent estimation of the fixed effects ordered logit model. Journal of the Royal Statistical Society, Series A 178: 685-703. https://doi.org/10.1111/rssa.12090. 
S15: Permission to use Measurement Scales (where open access for academic purposes is not specified)

Oldenburg Burnout Inventory

\section{Demerouti, E.}

Mon, 22 Jul, 09:15

Dear ----,

On behalf of professor Demerouti I would like to thank you for your interest in her burnout instrument. The OLBI is free of charge for academic purposes. In the attachment, you can find the OLBI in German and the unstandardized translation in English (checked by an American native speaker). As you will see in the meantime the scale has been improved in order to have equal number of positive and negative items.

If you decide to apply it eventually, please let us know whether the instrument has the same structure in your sample as in the German and the Dutch ones.

I have also attached some relevant publications as pdf files. We are looking forward to hearing your results.

Kind regards

Angela Jones

Secretary Human Performance Management Group

Department of Industrial Engineering and Innovation Sciences 


\section{Natalie Jean Allen}

Hello ----,

Thank you for your interest in using the Three-Component Model (TCM) Employee Commitment Survey in your research. You can get information about the measure, a Users' Guide, and the measure itself at:

http://employeecommitment.com/

For academic / research purposes, please choose the Academic Package. (There is no charge for this package.) I wish you well with your research!

Best,

Natalie Allen 